\title{
When cell biology meets development: endocytic regulation of signaling pathways
}

\author{
Elaine S. Seto, ${ }^{1,5}$ Hugo J. Bellen, ${ }^{1-4,6}$ and Thomas E. Lloyd ${ }^{2,5}$ \\ ${ }^{1}$ Program in Developmental Biology, ${ }^{2}$ Department of Molecular and Cellular Biology, ${ }^{3}$ Howard Hughes Medical Institute, \\ and ${ }^{4}$ Department of Molecular and Human Genetics, Baylor College of Medicine, Houston, Texas 77030, USA
}

Recent advances in membrane trafficking and signal transduction, once considered unrelated disciplines of cell biology, suggest that these fields are intimately intertwined. The sorting of signals and their receptors to different membrane-bound compartments plays a critical role in modulating the level and localization of signaling during development. Moreover, signaling pathways may interact with and regulate components of the membrane trafficking machinery. The relationship between these two fields is likely to be an area of intense future research as the interface of membrane trafficking and intercellular signaling appears to play an important role in development, physiology, and disease.

Recent work performed in many different systems has implicated nearly every membrane trafficking event as a potential site for the regulation of signaling pathways (Di Fiore and De Camilli 2001). The temporal and spatial delivery of signals and their receptors to different intracellular membrane-bound compartments is tightly regulated during development. Traditionally, endocytosis has been considered a mechanism to down-regulate receptors, desensitizing cells to signaling molecules. However, recent work has shown that endocytosis regulates signaling through multiple mechanisms. First, in receptor tyrosine kinase (RTK) signaling, endocytosis may increase signaling by associating internalized receptors with signaling targets localized to endosomes and decrease signaling by sorting receptors to the lysosome for degradation. Second, endocytosis may serve to regulate the distribution of signaling molecules. In the case of Wingless and transforming growth factor $\beta$ (TGF- $\beta$ )/Decapentaplegic (DPP), a form of endocytosis called transcytosis has been proposed to form morphogen gradients, and gradients can be shaped by controlling the recycling and degradation of internalized signaling molecules. Finally, internalization may be required to activate receptors, as is the case of Notch signaling. These proposed roles for endocytosis are likely to be important in the regulation of many signaling pathways during development.

\footnotetext{
${ }^{5}$ These authors contributed equally to this work.

${ }^{6}$ Corresponding author.

E-MAIL hbellen@bcm.tmc.edu; FAX (713) 798-3694.

Article and publication are at http://www.genesdev.org/cgi/doi/10.1101/ gad.989602.
}

Here we will review the process of endocytosis as well as the role that endocytosis plays in regulating developmental signaling. We will first summarize the general mechanisms of endocytosis, focusing on steps and proteins that have been shown to regulate signaling. Next, we will discuss emerging evidence implicating endocytosis in the regulation of developmental signaling pathways, including RTK, TGF- $\beta / D P P$, Hedgehog, Wingless, and Notch.

\section{Mechanisms of endocytosis}

Endocytosis refers to the trafficking of molecules into the cell through a series of vesicle compartments (Fig. 1). This process begins with internalization, the initial movement of molecules into a vesicle within the cell. Internalized molecules travel to the early endosome, where they are sorted to multiple locations such as recycling to the plasma membrane or trafficking to the lysosome for degradation.

Endocytosis can be broadly divided into two categories based on the material internalized. Phagocytosis /or cell eating) refers to the internalization of large particles (>200 nm) through an actin cytoskeleton-based mechanism (Caron and Hall 2001). Pinocytosis (or cell drinking) refers to internalization of extracellular medium and can occur through four basic mechanisms: clathrin-dependent endocytosis, caveolae-mediated endocytosis, macropinocytosis, and dynamin- and clathrin-independent endocytosis (Dautry-Varsat 2001). First, clathrin-dependent endocytosis involves the formation of vesicles using a clathrin coat, a process that is essential in nearly all cells. Second, caveolae-mediated endocytosis is believed to play a role in receptor-mediated endocytosis in many but not all cell types. Caveoli are small, flaskshaped membrane invaginations enriched in cholesterol, sphingolipids, and the protein caveolin. Third, macropinocytosis involves the formation of large vesicles that engulf extracellular fluid, a process mechanistically similar to phagocytosis. Finally, although the three mechanisms of pinocytosis described above all require dynamin, there is growing evidence that a dynamin- and clathrin-independent form of pinocytosis may exist. The mechanism and functional relevance of this form of endocytosis are not yet known. 


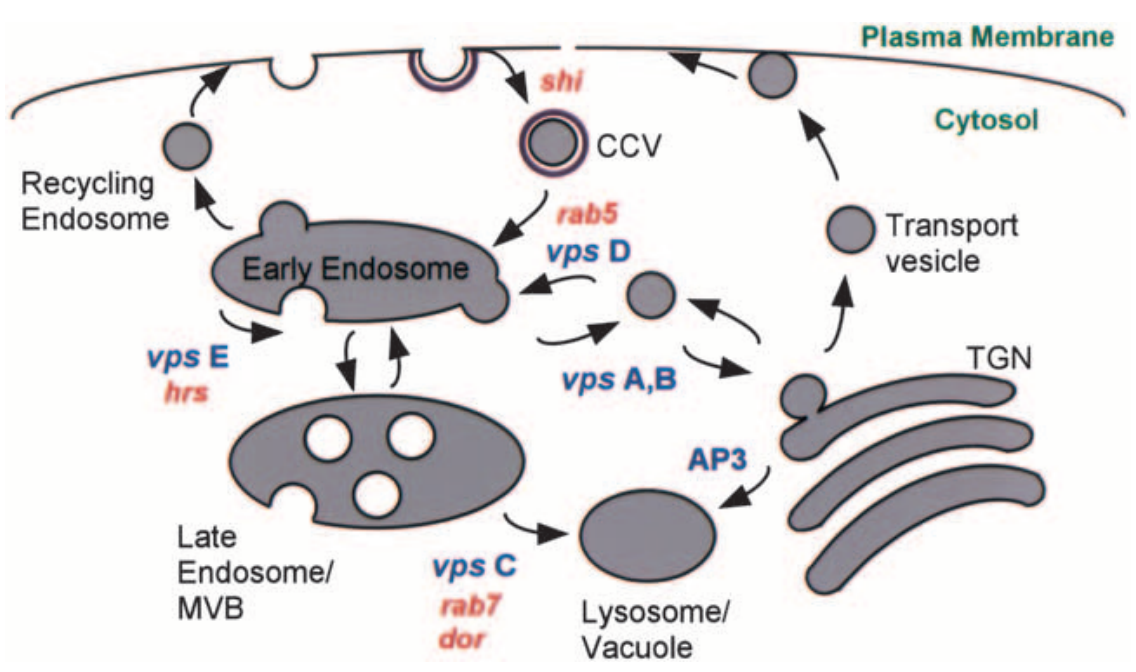

Figure 1. Endocytosis pathways and players. The early endosome accepts and delivers proteins and lipids from multiple membrane-bound compartments, including the plasma membrane (via recycling endosomes and clathrin-coated vesicles, CCVs), the Golgi (via transport vesicles from the trans Golgi network, TGN), and lysosome/vacuole (via late endosomes/multivesicular bodies, MVBs). Studies of endosomal sorting in yeast have identified key genes (vacuolar protein sorting, vps) involved in several of these steps which are grouped into classes (A-F) based on phenotype. In addition, a direct pathway for sorting from the TGN to vacuole in yeast has been described that requires the AP-3 complex. Mutations used to dissect the role of these pathways in development are shown in red.
Although receptor internalization occurs through several mechanisms, including phagocytosis and caveolaemediated endocytosis, we will focus on clathrin-mediated endocytosis in this review. Clathrin-mediated endocytosis is the best understood of these processes and has been clearly shown to play a critical role in the endocytosis of several receptor types. We will also be focusing on mechanisms of growth factor receptor internalization, because this process has been intensely investigated. However, the concepts presented are likely to apply to other receptors as well.

\section{Internalization of signaling molecules from the surface}

Clathrin-mediated internalization is initiated by the redistribution of membrane proteins into clathrin-coated pits (Brodsky et al. 2001). Transmembrane receptors bind directly or indirectly to the heterotetrameric adaptor complex AP-2 (Kirchhausen et al. 1997). This receptorAP-2 complex then binds clathrin, allowing clathrin to polymerize into a basket-shaped lattice that pulls membrane inside. This membrane invagination is thought to require localized alterations in phospholipid composition leading to changes in membrane curvature. One protein that may play an important role in altering membrane curvature is Endophilin, a lysophosphatidic acid acyltransferase that is required for the endocytosis of synaptic vesicles (Schmidt et al. 1999; Guichet et al. 2002; Verstreken et al. 2002). Once the inward budding of the membrane is complete, interactions between AP-2 and the GTPase Dynamin allows fission of the forming vesicle from the membrane (Wang et al. 1995; Ringstad et al. 1997). Recent data suggest that Dynamin tubulates the membrane by forming rings around the neck of budding vesicles and mediates vesicle fission either by altering its physical conformation alone or through the additional recruitment of other factors (McNiven 1998; Sever et al. 1999; van der Bliek 1999; Marks et al. 2001).

In addition to AP-2 and Dynamin, a third protein thought to play an essential role in clathrin-dependent endocytosis is Eps15. Eps15 is believed to nucleate the internalization complex through its protein-protein interactions. Eps 15 binds to NPF motif proteins such as Epsin and Numb (Wong et al. 1995; Iannolo et al. 1997; Chen et al. 1998; Santolini et al. 2000), and also forms homodimers and heterodimers with proteins such as Intersectin (Cupers et al. 1997). In addition, Eps 15 interacts with AP-2 and has been proposed to crosslink AP-2 complexes (Iannolo et al. 1997). Notably, yeast homologs of Eps15 have been shown to be essential for endocytosis (Raths et al. 1993; Wendland and Emr 1998). Vertebrate Eps15 has been shown to facilitate the internalization of the epidermal growth factor receptor (EGFR) and the transferrin receptor (Carbone et al. 1997; Benmerah et al. 1998). These studies point to an essential function of Eps15 family members in constitutive and ligand-mediated endocytosis.

AP-2 and other members of the endocytic machinery interact with cell membrane proteins through endocytic codes or motifs (Brodsky et al. 2001). Two basic classes of internalization sorting codes have been described for mammalian transmembrane proteins: tyrosine-based codes, including the NPXY and YXXØ /where $\varnothing$ is a hydrophobic amino acid), and dileucine motifs. These internalization-sorting signals may be modified by posttranslational modification, which may serve to regulate both constitutive and ligand-activated endocytosis. Phosphorylation of residues within or adjacent to the internalization motifs has been shown to affect receptor internalization, and may be responsible for the increased rate of internalization observed after ligand binding (Dietrich et al. 1994; Dittrich et al. 1996; Pitcher et al. 1999|. In addition, endocytic motifs can be ubiquitinated. In yeast, monoubiquitination of surface membrane proteins, such as the G-protein coupled receptor (GPCR) Ste2p, is required for ligand-stimulated internalization (Rotin et al. 2000). This internalization may be facilitated through interactions between Eps 15 and the ubiquitin ligase Rsp5p, which is required for receptormediated endocytosis (Galan et al. 1996; Zoladek et al. 1997; Polo et al. 2002). Therefore, the endocytic motifs 
can be phosphorylated and ubiquitinated, altering the internalization of cell surface proteins.

\section{Early endosome fusion}

After proteins are internalized into clathrin-coated vesicles (CCVs) (Fig. 1), the clathrin coat is rapidly disassembled via the concerted action of Auxilin, heat shock proteins, and Synaptojanin (Holstein et al. 1996; Cremona et al. 1999; Newmyer and Schmid 2001). These small, primary endocytic vesicles then fuse with the early endosome, and early endosomes fuse with one another. The mechanism of early endosome fusion has been well characterized using both yeast genetic screens and mammalian homotypic fusion reconstitution assays (Stenmark and Zerial 2001). In the latter approach, endosome fractions are isolated from two cell populations, one incubated with a tag linked to avidin, and the other with an enzyme linked to biotin. When mixed, the endosomes fuse, and pulldown of the tag coprecipitates enzymatic activity. Using this assay, cytosolic components required for early endosome fusion have been identified.

One of the first cytosolic proteins found to be essential using this assay was the small GTPase Rab5. Rab5 is localized to early endosomes (Chavrier et al. 1990; Bucci et al. 1992), and immunodepletion prevents homotypic fusion, suggesting that Rab5 may be necessary for endosome fusion (Gorvel et al. 1991). A Rab5 mutation that preferentially binds GDP (S34N) inhibits endocytosis and results in the formation of very small endosomes, whereas a constitutively active, GTPase-deficient form (Q79L) stimulates endocytosis and results in the formation of enlarged early endosomes (Stenmark et al. 1994). Since its identification, at least 22 potential effectors of Rab5 have been isolated, consistent with the multiple proposed functions for Rab5 in the early steps of endocytosis, including internalization, early endosome fusion, and movement of endocytic vesicles along microtubules (Fig. 1; Horiuchi et al. 1997; McLauchlan et al. 1998; Christoforidis et al. 1999b; Nielsen et al. 1999).

Perhaps the most important effector of Rab5 function in endosome fusion is the cytosolic protein early endosome antigen-1 (EEA-1). Homotypic fusion experiments revealed that EEA-1 is required for endosome fusion, and at high levels, it is the only cytosolic factor necessary for fusion (Christoforidis et al. 1999a). EEA-1 localizes to endosome membranes through its amino-terminal phosphatidyl inositol-3-phosphate [PI(3)P]-binding FYVE domain (Stenmark et al. 1996). PI(3)P is highly enriched in early endosomes, possibly due to interactions between Rab5-GTP and the PI(3)-kinase hVps34 (Christoforidis et al. 1999b; Gillooly et al. 2000). Notably, blocking PI(3)kinase activity using wortmannin prevents endosome fusion, but this requirement for PI(3)P can be bypassed by high levels of EEA-1 or active Rab5 (Li et al. 1995; Simonsen et al. 1998). Thus, Rab5-GTP is able to recruit EEA-1 to early endosome membranes directly by binding EEA-1 and indirectly by stimulating localized production of $\mathrm{PI}(3) \mathrm{P}$. Once localized to the endosome mem- brane, EEA-1 most likely serves to tether endosomes together by forming homodimeric complexes through its coiled-coil domain (Christoforidis et al. 1999a).

As with all known membrane fusion events, the fusion of endosomes requires the formation of SNARE (soluble $\underline{N}$-ethylmaleimide-sensitive factor attachment protein receptor) complexes that form a bridge between membranes. Several SNARE proteins are localized to early endosomes, including multiple Syntaxin and VAMP family members, and are all potential candidates for mediating endosome fusion (Hazuka et al. 1999). Notably, EEA-1 forms a high molecular weight complex with Syntaxin 13 that also contains Rab5 effectors (McBride et al. 1999). Furthermore, disruption of the EEA1Syntaxin 13 interaction with a dominant negative Syntaxin13, anti-Syntaxin13 antibody, or an EEA-1 peptide inhibits the endosome fusion reaction. These data suggest that in addition to a role in endosome tethering, EEA-1 may also regulate fusion of early endosome membranes by affecting SNARE complex formation.

\section{Endosomal sorting and late endosome formation}

In addition to the plasma membrane, early endosomes also accept cargo from the Golgi and late endosome, and then redistribute cargo to these same three locations (Fig. 1). For example, cell surface proteins and lipids can be sorted from the early endosome to either the surface for recycling or to the lysosome for degradation. Lysosomal degradative enzymes are manufactured in the Golgi and can be transported to the lysosome directly through the AP-3 pathway or indirectly through the endosome (Cowles et al. 1997). Transport proteins that carry degradative enzymes to the lysosome must then be recycled back to the Golgi. Interestingly, genes in the direct AP-3 pathway have been shown to be required for the formation of pigment granules, and mutations in Drosophila and mouse AP-3 subunits lead to eye and coat color phenotypes, respectively (Lloyd et al. 1998; Odorizzi et al. 1998b). Not surprisingly, this vast array of membrane trafficking events requires a complex network of players to get the right cargo to the right place.

Little is known about the proteins that select cargo from the endosome and recycle it to the surface. Recycling endosomes are believed to bud off early endosome membranes and then fuse with the plasma membrane. These events may be mediated by Rab4, Rab11, and the SNARE protein Cellubrevin, all of which are present on recycling vesicles (Peters et al. 2001). Although this process is not well understood, recycling may be extremely important in the context of morphogen gradient formation where transcytosis, a process of sequential internalization at one cell surface and release at the opposite cell surface, may mediate morphogen movement through tissues.

Other sorting events from the early endosome are better understood due to genetic screens performed in yeast. These screens were based on defective sorting of the enzyme carboxypeptidase Y (CPY) from the Golgi to the 
vacuole (the yeast version of the lysosome; Bankaitis et al. 1986; Rothman and Stevens 1986). Based on the observation that overexpression of CPY results in enzyme secretion into the medium (Stevens et al. 1986), investigators reasoned that strains defective in trafficking CPY from the Golgi to the endosome, or from the endosome to the vacuole, would result in a similar phenotype. Indeed, by selecting for mutants that secrete CPY, $>40$ complementation groups (genes) defective in vacuolar protein sorting (vps) were isolated. These genes were then grouped into six different classes $(\mathrm{A}-\mathrm{F})$ based on vacuolar morphology (Robinson et al. 1988; Raymond et al. 1992). This classification has proven to be quite accurate in predicting in which step of the endocytic pathway these genes function (Fig. 1).

In addition to genetic screens in yeast, considerable work has been performed in vertebrate cells to investigate trafficking from the endosome. There has been some debate as to whether transport vesicles move cargo between early and late endosomes, or alternatively, whether early endosomes mature to form late endosomes (Griffiths and Gruenberg 1991; Murphy 1991). Regardless of which model proves correct, early and late endosomes may be distinguished based on time to reach the compartment from the surface, membrane markers, location within the cell, $\mathrm{pH}$, and morphology. Though heterogeneous, mammalian early endosomes tend to be peripherally located and have a tubulo-vesicular morphology, whereas late endosomes tend to be perinuclear, more acidic, and spherical. Characteristically, late endosomes contain internal vesicles (Hopkins et al. 1990), and for this reason, are often referred to as multivesicular bodies (MVBs) or multivesicular endosomes (Fig. 1; Piper and Luzio 2001). These internal vesicles of MVBs are enriched in PI(3)P and lysobisphosphatidic acid (LBPA) phospholipids (Kobayashi et al. 1998; Gillooly et al. 2000).

The mechanism of formation of inner vesicles of MVBs is poorly understood. It has been proposed that budding of inner vesicles may mechanistically resemble clathrin-coated vesicle formation. However, for the same mechanism to apply, the internalization machinery would have to lie topologically inside the endosome (Figs. 1, 2). For instance, at the cell surface, dynamin is present in the cytosol to pinch off the forming vesicle; however, at the endosome, dynamin is present outside of the endosome and can not mediate vesicle formation through the same mechanism. It is therefore likely that a very different mechanism involving cytoplasmic factors causes inward budding of the endosome membrane.

The first clue of the mechanism of MVB formation came relatively recently following studies of carboxypeptidase S (CPS) sorting in yeast. CPS is synthesized as a transmembrane protein, sorted into a vesicle within the vacuole lumen, and then cleaved (Spormann et al. 1992; Odorizzi et al. 1998a). Class E vps mutants fail to sort CPS inside the vacuole lumen, and a similar phenotype is observed in the mutant Fablp, a FYVE domaincontaining PI(3)P 5' kinase, which is completely devoid of vesicles within the vacuole. These data suggest that

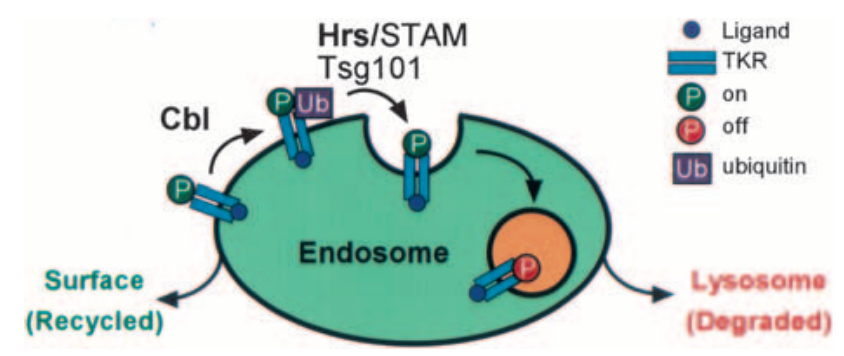

Figure 2. Endososomal sorting of receptor tyrosine kinases. On ligand binding, dimerization, and autophosphorylation, receptor tyrosine kinases (RTKs) are rapidly internalized into early endosomes. Ubiquitination of RTKs by Cbl serves as a signal for degradation in the lysosome whereas nonubiquitinated RTKs are recycled to the surface. Class E vps proteins such as HGFregulated tyrosine kinase substrate (Hrs), STAM, and Tsg101 induce endosome membrane invagination, leading to multivesicular body (MVB) formation. Active RTKs are deactivated by sorting into inner vesicles of the MVB, which are then degraded by trafficking to the lysosome. Ubiquitinated RTKs may be sorted into MVBs via an interaction of ubiquitin with the ubiquitin-interacting motif (UIM) of Hrs and the signal-transducing adaptor molecule (STAM) or with the ubiquitin conjugating (UBC) domain of Tsg101. RTKs not internalized into the endosome may still be active, so in this model, MVB formation terminates receptor signaling.

the function of class E proteins is to sort cargo into inner MVB vesicles.

Recently, the signal for sorting CPS and other proteins into the MVB was identified to be ubiquitin. Mutating the ubiquitinated lysine residue of CPS results in failure to sort CPS to the inner vesicles of MVBs. Furthermore, ubiquitination is also sufficient for this sorting step, as fusion of ubiquitin to the carboxyl terminus of proteins present on the vacuole membrane leads to their trafficking into inner vesicles. Notably, the class E protein Vps23p is capable of binding ubiquitin through its ubiquitin conjugating (UBC)-like domain (Katzmann et al. 2001). This UBC domain is essential for sorting CPS inside the vacuole lumen. In addition, Vps23p forms a high molecular weight complex with two other class E proteins, Vps28p and Vps37p, which has been termed ESCRT-1 (endosomal sorting complex required for transport). The ESCRT-1 complex likely médiates the sorting of ubiquitinated proteins like CPS into internal vesicles of the multivesicular body for eventual delivery to the vacuole/lysosome. Thus, in addition to proteasome-mediated degradation, ubiquitination of proteins may also target them for lysosome-mediated degradation.

In summary, proteins and lipids undergo a series of sorting events that determine their trafficking. First, cargo travels to the early endosome where it is sorted to the Golgi, to recycling vesicles for return to the plasma membrane, or to late endosomes. At the late endosome, proteins can remain on the limiting outer membrane or be further sorted into inner lumenal vesicles if the proteins are ubiquitinated. The end result is the formation of a multivesicular body, which is then delivered to the lysosome for degradation. 


\section{Late endosome to lysosome trafficking}

Late endosomes and lysosomes share many characteristics including low $\mathrm{pH}$, perinuclear distribution, and specific integral membrane glycoproteins, however degradation occurs primarily within the lysosome (Piper and Luzio 2001). After class $\mathrm{E}$ proteins sort receptors into the $\mathrm{MVB}$, the class $\mathrm{C}$ proteins mediate late endosome to lysosome fusion (Fig. 1; Seaman and Luzio 2001). Vertebrate homologs of class C vps SNARE proteins such as Syntaxin 7 have been shown to play a role in heterotypic fusion of late endosomes with lysosomes (Mullock et al. 2000). On fusion, degradative enzymes within the lysosome digest lumenal protein and lipid components, including the inner MVB vesicles. Hybrid organelles with characteristics of both late endosomes and lysosomes have been rarely observed, suggesting lysosomes are rapidly reformed following fusion with the late endosomes.

This concludes our overview of endocytosis and the key players that regulate this complex process. In the following sections, we will attempt to illustrate how specific developmental signaling pathways fit within this framework of vesicle trafficking and describe three overall effects of endocytosis on signaling. First, endocytosis may modulate signaling levels, as in receptor tyrosine kinase and TGF- $\beta$ signaling. Second, endocytosis may play a critical role in morphogen gradient formation for DPP, Hedgehog, and Wingless. Finally, in Notch signaling, endocytosis may be necessary to activate signaling. Although endocytosis regulates signaling, signaling may also regulate the endocytic machinery, providing a mechanism through which signaling pathways modulate themselves and other pathways.

\section{RTK signaling}

There are many types of RTKs, however, they all activate signaling through similar mechanisms. Ligand binding to RTKs induces receptor dimerization and autophosphorylation in trans. Activated RTKs typically signal through interactions between their tyrosine-phosphorylated cytoplasmic domain and proteins that contain SH2 or PTB (phosphotyrosine binding) domains. These protein interactions usually initiate enzymatic cascades resulting in activation of transcription factors and induction of gene expression. For example, binding of the SH2 domain protein Sos to EGFR activates Ras, thereby triggering the mitogen-activated protein kinase (MAPK) pathway and activating expression of target genes. The relationship between receptor tyrosine kinase signaling and endocytosis has been intensely studied for over 20 years and has been the subject of several recent reviews (Leof 2000; Waterman and Yarden 2001). Therefore, we will focus on recent findings. We have divided a summary into two parts: the role that RTK signaling plays in regulating endocytosis and the role that endocytosis plays in regulating RTK signaling.

\section{RTK signaling regulates endocytosis}

Over the last five years, data has accumulated to suggest that RTK signaling regulates the endocytosis machinery.
In fact, some proteins seem to play an integral role in both endocytosis and signaling. Receptor tyrosine kinase activity appears to regulate receptor internalization through phosphorylation of downstream target proteins (Glenney et al. 1988; Chen et al. 1989; Felder et al. 1990; Honegger et al. 1990; Lamaze and Schmid 1995). A large number of proteins implicated in endocytosis are tyrosine phosphorylated by RTKs (see below), and perhaps the best candidate for the required phosphorylation substrate is the protein Eps15. Eps15 is known to be recruited to clathrin-coated pits in response to EGFR activation, and EGFR-mediated phosphorylation of Eps15 has been shown to be specifically required for ligandinduced internalization of EGFR /Confalonieri et al. 2000).

In addition, many downstream targets of RTK signaling directly regulate components of the endocytosis machinery. For example, the tyrosine kinase Src regulates clathrin-mediated endocytosis via multiple mechanisms. Src phosphorylates the clathrin heavy chain, stimulating clathrin-coated pit formation (Wilde et al. 1999), and its SH3 domain can bind and activate Dynamin (Gout et al. 1993). Consistent with these findings, overexpression of Src stimulates EGFR endocytosis (Ware et al. 1997). Receptor internalization may also be regulated by Ras-mediated activation of the small GTPase Ral (Di Fiore and De Camilli 2001). Both RalBP1 (Ral binding protein 1) and its associated protein POB1 ( Partner of $\underline{B} \overline{1} 1)$ have been shown to play important roles in RTK internalization. Finally, RTK signaling may also regulate the activity of Rab5. RTK activity has been shown to stimulate the activity of both a Rab5-GAP and a Rab5-GEF, suggesting that RTK signaling plays a role in both the activation and deactivation of Rab5. Thus, RTK activity may have both positive and negative effects on its endocytosis, a feedback system that may allow activity-dependent fine tuning of receptor internalization.

\section{Endocytosis regulates RTK signaling}

A role for endocytosis in the regulation of RTK signaling was first proposed in the late 1970s when it was observed that the EGFR was internalized following application of ligand (Haigler et al. 1979). Since the mid-1980s, the role that endocytosis plays in regulating EGFR signaling has been the subject of intense investigation and controversy (Leof 2000; Ceresa et al. 2001). Initially, it was proposed that receptor internalization led to trafficking of the receptor to the nucleus where it activated transcription. Little support has been given to this model, although activated EGFR family members have been recently observed in the nucleus of some cells and have been proposed to directly induce gene transcription (Lin et al. 2001). The majority of studies support one of the following two models of endocytic regulation.

In the first model, receptor internalization attenuates RTK signaling, possibly by trafficking the active EGFR to the lysosome where it can be degraded. Expression of internalization-defective EGFR induces transformation 
of cells by delivering constitutive mitogenic signals in response to ligand (Wells et al. 1990). Furthermore, heterodimers composed of human RTKs ErbB-1 (EGFR) and ErbB-2, which have reduced internalization capability, prolong signaling when compared with EGFR homodimers (Lenferink et al. 1998). These studies suggest that disrupting RTK internalization results in an inability to attenuate signaling.

In the second model, receptor internalization facilitates signaling by bringing the active receptor to certain downstream targets within the cell. On endosomes, activated EGFR maintains its kinase activity and becomes increasingly phosphorylated (Cohen and Fava 1985; Lai et al. 1989). Furthermore, the receptor associates with downstream targets such as Shc, Grb2, PI3K, Ras, and mSOS on endosomes. Most of the Shc and PI3K phosphorylated in response to EGFR activation has been detected in endosome fractions (DiGuglielmo et al. 1994; Oskvold et al. 2000). Thus, signaling occurs at the endosome, but does internalization enhance signaling?

Studies performed in HeLa cells overexpressing dominant negative Dynamin suggest that EGFR internalization may serve to activate specific downstream targets. When EGFR internalization is blocked, there is no effect on Shc activation, but MAPK phosphorylation is decreased (Vieira et al. 1996). This reduced ability to activate MAPK appears to be caused by decreased phosphorylation of MAPK by MEK-1, as upstream kinase substrates Ras, Raf, and MEK-1 are phosphorylated at normal levels (Kranenburg et al. 1999). These data suggest that the endosomal localization of receptors may selectively activate specific downstream targets. Notably, internalization results in phosphorylation of different residues of activated EGFR, which may result in the signal specificity observed (Nesterov et al. 1994). Therefore, the compartmentalization of EGFR may promote signaling through select targets, providing an additional layer of signal specificity.

In summary, evidence suggests that internalization mediates both RTK signaling and signal attenuation. How might these findings be reconciled? The answer may lie in what happens after internalization during endosomal sorting.

\section{Role of sorting in regulating RTK signaling}

It is likely during endosomal sorting that the ultimate fate of receptors and the impact of endocytosis on signaling are determined. Receptors may be sorted to recycling endosomes and return to the surface or trafficked to the lysosome for degradation. These trafficking decisions likely have important consequences for receptor signaling. Several pieces of evidence suggest that sorting decisions may take place at the level of the MVB. Receptors that are destined for degradation in the lysosome such as activated EGFR are sorted into the internal vesicles of the MVB (Fig. 2), whereas other receptors destined for recycling such as inactive EGFR and the transferrin receptor remain at the limiting outer membrane (Felder et al. 1990; Hopkins et al. 1990; Futter et al. 1996). These data imply that the sorting of receptors into MVBs for lysosomal degradation is ligand-dependent.

Recently, evidence has suggested that ubquitination of EGFR may result in sorting into the MVB for eventual degradation. The gene $c b l / s l i-1$ has been identified as a negative regulator of receptor tyrosine kinase signaling in Caenorhabditis elegans and Drosophila (Yoon et al. 1995; Pai et al. 2000). c-Cbl binds the EGFR directly via a PTB domain, and, as shown in Figure 2, can ubiquitinate EGFR through its RING finger ubiquitin ligase domain (Levkowitz et al. 1998, 1999; Joazeiro et al. 1999). $\mathrm{v}-\mathrm{Cbl}$, a virally produced truncation of $\mathrm{cbl}$ lacking the RING domain, fails to down-regulate signaling (Langdon et al. 1989; Lill et al. 2000). Studies overexpressing Dynamin K44A, a mutant that blocks endocytosis, suggest that EGFR is ubiquitinated on the plasma membrane (Stang et al. 2000). Consistent with a function at the plasma membrane, $\mathrm{Cbl}$ has been found recently to form a complex with active RTKs and Endophilin and has been proposed to regulate RTK internalization (Petrelli et al. 2002; Soubeyran et al. 2002). However, immunolocalization studies have suggested that $\mathrm{Cbl}$ is recruited to endosomes following EGFR internalization (Meisner et al. 1997; Levkowitz et al. 1998; Burke et al. 2001). An endosomal function for $\mathrm{Cbl}$ is suggested by the finding that c-Cbl overexpression does not alter EGFR internalization, but rather down-regulates EGFR by inhibiting receptor recycling (Levkowitz et al. 1998). Conversely, $\mathrm{v}-\mathrm{Cbl}$ overexpression promotes EGFR recycling. Furthermore, other ErbB RTK family members (ErbB-2, ErbB-3, and ErbB-4) that are unable to bind $\mathrm{Cbl}$ are recycled to the cell surface rather than targeted to the lysosome (Waterman et al. 1999). In addition, an EGFR tyrosine residue (Y1045) known to be required for lysosomal targeting of the receptor is also required for c-Cbl-dependent ubiquitination (Levkowitz et al. 1999). Although indirect, these data suggest that Cbl-mediated ubiquitination of EGFR down-regulates signaling by sorting the receptor to the lysosome for degradation.

In yeast, the sorting of ubiquitinated proteins into inner MVB vesicles is performed by class E vps proteins. Though RTKs are not present in yeast, ligand activation of the GPCR Ste2p leads to its internalization and sorting to the vacuole for degradation, a process known to require class E vps function (Odorizzi et al. 1998a). This suggests that members of the class E vps pathway in multicellular organisms might also function in sorting receptors to the lysosome. Indeed, the human homolog of the class E protein Vps23p, Tsg101, reduces EGF recycling when compared to wild-type cells (Babst et al. 2000). However, the suppressive effect of wild-type Tsg101/Vps23 on proliferation may be attributable to effects on the p53/MDM2 pathway in addition to lysosomal degradation of EGFR (Li et al. 2001).

Another class E protein implicated in endosomal trafficking and signaling is Hrs (hepatocyte growth factor [HGF]-regulated tyrosine kinase substrate), the homolog of the yeast protein Vps27p (Komada and Kitamura 2001). Consistent with the VPS27 mutant phenotype, Hrs mutants have enlarged endosomes caused by an in- 
ability of endosomes to invaginate their limiting membrane to form multivesicular bodies (Fig. 2; Piper et al. 1995; Komada and Soriano 1999; Lloyd et al. 2002). In hrs mutant flies, active Torso and EGF RTKs fail to be downregulated (Lloyd et al. 2002). This leads to enhanced signaling, suggesting that Hrs-mediated receptor sorting into inner MVB vesicles is required to attenuate signaling. Notably, Hrs interacts with two other proteins that have been implicated in EGFR degradation, SNX-1 and STAM. SNX-1 (Sorting Nexin-1) potentiates active EGFR down-regulation by binding to a lysosomal targeting motif on the receptor (Opresko et al. 1995; Kurten et al. 1996). Members of the STAM (signal-transducing adaptor molecule) family are homologous to the class E protein YHL002w (Piper and Luzio 2001), and have been implicated in the regulation of several signaling pathways (Asao et al. 1997; Takeshita et al. 1997; Takata et al. 2000). One of the STAM proteins interacts directly with the EGFR (Lohi et al. 1998). Interestingly, the class E proteins Hrs and STAM both contain VHS (Vps27p, Hrs, STAM) domains, which may bind to membranes and/or receptors, and a ubiquitin-interacting motif (UIM), which may allow for the sorting of ubiquitinated receptors into the MVB (Lohi and Lehto 1998; Hofmann and Falquet 2001; Tooze 2001; Lloyd et al. 2002). These data suggest that Hrs, Sorting Nexin-1, and the STAM proteins down-regulate signaling by sorting receptors to the lysosome through interactions with ubiquitin and/or the cytoplasmic domain of the receptor (Fig. 2).

In summary, multiple steps of endocytosis have been shown to regulate RTK signaling. Although RTK internalization is required for its down-regulation, this initial step of endocytosis may also allow maximal signaling by delivering receptors to downstream targets localized to endosomes. Recent data suggests that endosomal sorting of ubiquitinated RTKs plays a critical role in determining the strength and duration of signaling during development. Although the role endocytosis plays in signaling has been characterized best for RTKs, recent data indicates that endocytosis plays an important role in regulating many important developmental signaling pathways.

\section{TGF- $\beta$ signaling}

Signaling through the TGF- $\beta$ superfamily of secreted polypeptides performs a staggering array of functions throughout the organism. The bone morphogenetic proteins (BMPs) form the largest group within the TGF- $\beta$ family and have been shown to play critical roles in several developmental processes including bone development, neural tube polarity, left-right axis formation, and limb development. Notably, alterations in TGF- $\beta$ family signaling have been shown to contribute to many types of human cancer, highlighting their importance in regulating cell proliferation, migration, differentiation, and cell death (Massague 2000; Derynck et al. 2001).

TGF- $\beta$ family members mediate their functions through transmembrane serine/threonine kinases known as type I and type II TGF- $\beta$ receptors. Binding of the dimeric ligand to specific type II receptors initiates the recruitment of type I receptors to form heteromeric receptor complexes. Once phosphorylated by the type II receptors, the type I receptor kinases are capable of directly phosphorylating and activating one of the two subfamilies of receptor-regulated Smad proteins (R-Smads). R-Smad activation can be prevented by the inhibitory Smad proteins (I-Smads), Smad6 and Smad7, which obstruct R-Smad association with the receptor complex. Activated R-Smads are able to associate with Smad4, the common-mediator Smad, and translocate into the nucleus where the complex regulates the transcription of target genes through cooperative interactions with DNA and other DNA-binding proteins (Massague 1998). Allowing for the wide range of functions performed by TGF- $\beta$ family members in different cell types, the specificity of TGF- $\beta$ signaling appears to be determined by a combination of the extent of ligand binding, the type of R-Smad subfamily activated, and the DNA-binding proteins available within the cell.

\section{TGF- $\beta$ receptor regulation}

Unlike growth factor RTKs, the role of endocytosis in TGF- $\beta$ receptor regulation has not been studied extensively. However, TGF- $\beta$ receptors are localized to the plasma membrane as well as to intracellular vesicles (Zwaagstra et al. 1999), and studies using radioactively labeled ligand suggest that TGF- $\beta$ undergoes rapid receptor-mediated internalization (Massague and Kelly 1986; Sathre et al. 1991). Furthermore, cells treated with the lysosomal inhibitor chloroquine showed intracellular accumulations of ligand, indicating that TGF- $\beta$ undergoes lysosomal degradation. However, the effects of ligand binding on surface receptor levels have been unclear, with reports ranging from no change to a $50 \%$ reduction (Frolik et al. 1984; Wakefield et al. 1987). One source of variability in these experiments may be the high levels of nonspecific ligand binding (Anders et al. 1997). Furthermore, with the identification of both heteromeric receptor complexes (type I-type II) and homomeric receptor complexes (type I-type I and type II-type II), the possibility arose that the various receptor complexes were differentially internalized, adding an additional level of complexity to TGF- $\beta$ endocytosis (Chen et al. 1993; Henis et al. 1994).

To clarify the role of endocytosis in TGF- $\beta$ signaling, chimeric receptors consisting of a foreign ligand-binding domain fused to either a type I or type II TGF- $\beta$ receptor have been used. These chimeric receptors allow for specific binding of radioactively labeled ligand and defined receptor complex formation (Anders and Leof 1996; Muramatsu et al. 1997). Inhibition of clathrin lattice formation by cytoplasmic acidification significantly reduced the number of vesicles containing TGF- $\beta$ receptor complexes, suggesting that internalization of these chimeric receptors occurs via a clathrin-mediated process (Anders et al. 1997). Both heteromeric and homomeric TGF- $\beta$ 
receptor complexes undergo ligand-dependent internalization. Once internalized, if the ligand dissociates from the complex, TGF- $\beta$ receptors are constitutively recycled to the cell surface similar to the constitutive recycling observed for EGFR (Dore et al. 1998, 2001). However, if the ligand is associated with the complex, the TGF- $\beta$ receptors can be targeted for either recycling or lysosomal degradation depending on the complex composition. Homomeric receptor complexes are unable to activate signaling and are not degraded, whereas heteromeric receptor complexes are down-regulated (Anders et al. 1997). Notably, the few studies using full length TGF- $\beta$ receptors have generally supported a role for internalization in receptor down-regulation, however, some aspects of the chimeric receptor model, such as whether internalization is clathrin-dependent, have been called into question (Zwaagstra et al. 1999, 2001; Ehrlich et al. 2001).

As described previously, kinase activity of the EGFR is critical to its signaling and internalization. The TGF- $\beta$ type II receptor has two kinase activities, phosphorylating itself (autophosphorylation) or its type I partner (transphosphorylation) (Wrana et al. 1992, 1994; Franzen et al. 1995; Wieser et al. 1995). The transphosphorylation activity of the type II receptor and the kinase activity of the type I receptor are required for TGF- $\beta$ signal transduction. Kinase requirements for internalization, however, vary according to the cell type studied. In mesenchymal cells, the transphosphorylation activity of the type II receptor is needed for optimal internalization and receptor downregulation, whereas kinase activity of the type I receptor is not required (Anders et al. 1998). In contrast, in epithelial cells, type II transphosphorylation activity is not strictly needed for receptor down-regulation (Dore et al. 2001). Therefore, although TGF- $\beta$ signaling requires both type I and type II kinase activity in all cell types, mesenchymal and epithelial cells have different kinase requirements for receptor complex internalization and down-regulation.

The different receptor kinase requirements in mesenchymal and epithelial cells suggest that differential regulation of internalization may reflect a mechanism through which TGF- $\beta$ signaling specificity is achieved. In mesenchymal cells, heteromeric and homomeric receptor complexes are internalized at similar rates, whereas, in epithelial cells, heteromeric complexes appear to be internalized faster and to a greater extent than homomeric complexes (Dore et al. 1998). Differences in the relative rates of heteromeric and homomeric receptor complex internalization may affect signaling levels. In epithelial cells, for example, the decreased internalization of homomeric complexes may increase surface receptor levels relative to mesenchymal cells. Therefore, equal levels of ligand binding might produce higher levels of heteromeric complex formation and internalization in epithelial cells than in mesenchymal cells. This differential regulation of TGF- $\beta$ receptor internalization may explain how TGF- $\beta$ signaling can stimulate growth in mesenchymal cells, while inhibiting growth in epithelial cells.

\section{Regulation of Smad proteins}

Although internalization regulates TGF- $\beta$ signaling by down-regulating receptor levels, recent evidence has suggested that endocytosis may also regulate Smad protein levels. For example, Smurf proteins are E3 ubiquitin ligases that inhibit TGF- $\beta$ signaling and ubiquitinate both TGF- $\beta$ receptors and Smad proteins. As was stated previously, protein ubiquitination can serve as a signal for internalization, proteosome-mediated degradation, or lysosome-mediated degradation (Hicke 2001). Three predominant mechanisms have been proposed to explain how Smurfs inhibit signaling (Fig. 3B). First, the Smurf proteins may ubiquitinate the R-Smads, Smadl and Smad2, leading to their degradation (Zhu et al. 1999; Lin et al. 2000). Second, Smurfs may target Smad7 to the receptor where the I-Smad can block R-Smad activation (Kavsak et al. 2000; Ebisawa et al. 2001). Finally, the Smurfs may tag the Smad7-receptor complex for degradation, thereby reducing the amount of receptor available for ligand binding. The degradative processes mentioned above can be partially blocked using proteosome inhibitors, suggesting that the protein levels are regulated at least in part through proteosome-mediated degradation. However, studies using the lysosomal inhibitor chloroquine have suggested that Smad7 and TGF- $\beta$ receptor levels are also regulated through lysosomal trafficking (Kavsak et al. 2000). Therefore, ubiquitination of the Smad7-receptor complex results in sorting the proteins into MVBs for lysosomal degradation. Although the degradation of R-Smads has not been studied in the presence of chloroquine, it is possible that Smurf proteins regulate TGF- $\beta$ signaling through both proteosome-mediated and lysosome-mediated degradation. Interestingly, Drosophila Smurf mutants have an expanded TGF- $\beta$ gradient and fail to down-regulate signaling, leading to marked developmental defects (Podos et al. 2001). Thus, the Smurf proteins play a critical role in regulating TGF- $\beta$ signaling during development, possibly by targeting proteins for ubiquitin-mediated lysosomal degradation.

Another proposed regulator of TGF- $\beta$ signaling is the protein AMSH lassociated molecule with the $\underline{\mathrm{SH}} 3$ domain of STAM). AMSH has been shown to bind directly to STAM (Tanaka et al. 1999), a protein that has been implicated in both endocytosis and signaling. As described previously, STAM has been proposed to regulate the degradation of receptor tyrosine kinases through its interactions with Hrs. Interestingly, AMSH has been shown to bind the I-Smad Smad6 upon receptor activation and promotes BMP signaling when overexpressed (Itoh et al. 2001). Thus, AMSH may regulate Smad6 activity and BMP signaling through interactions with the endosomal proteins STAM and Hrs.

Another potential link between TGF- $\beta$ signaling and endocytosis is the Smad2-interacting protein SARA ( Smad anchor for receptor activation; Tsukazaki et al. 1998). SARA contains a highly conserved FYVE domain, which has been shown to bind $\mathrm{PI}(3) \mathrm{P}$ and localize pro- 


\section{(A) ACTIVATION}

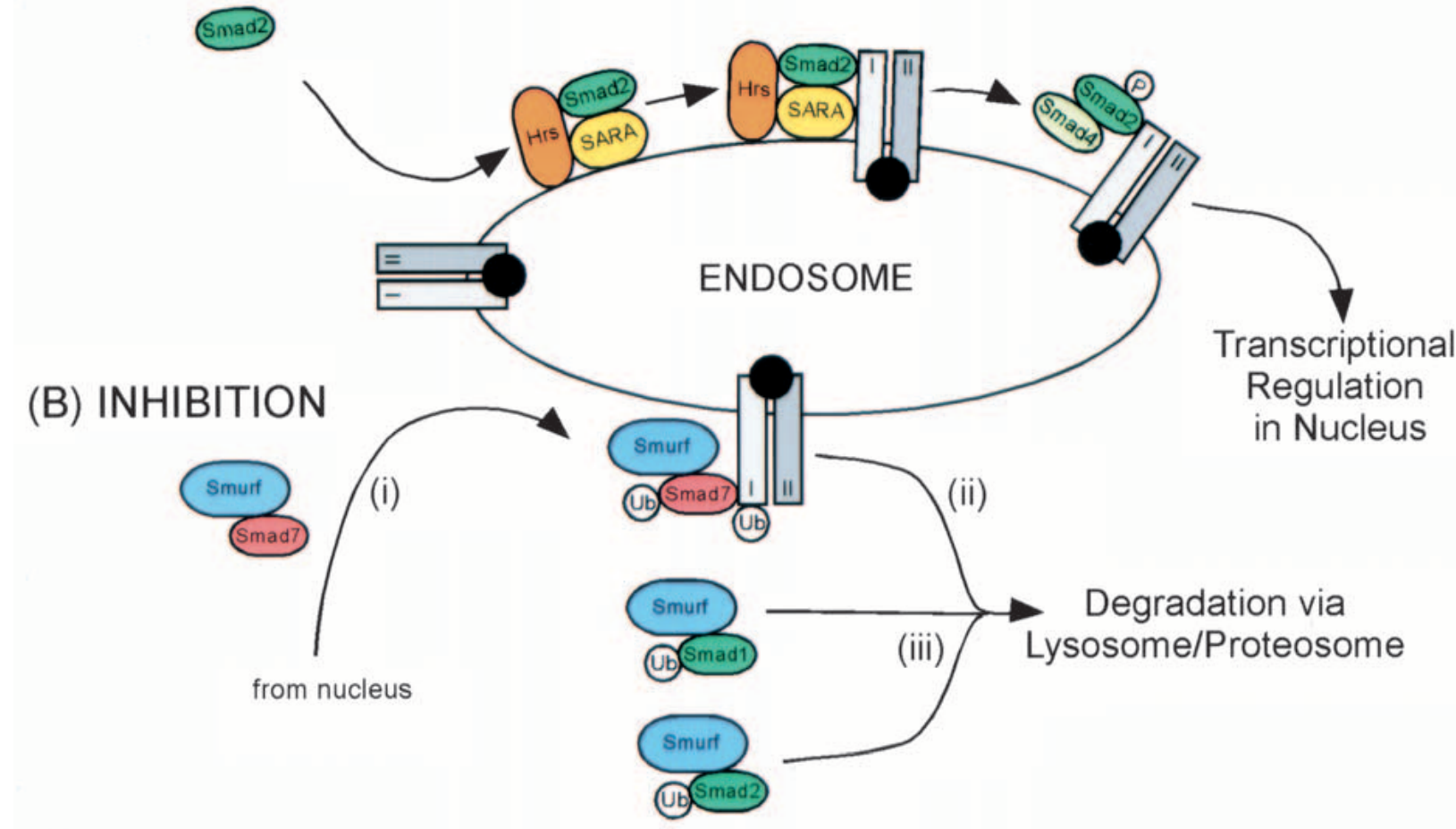

(C)

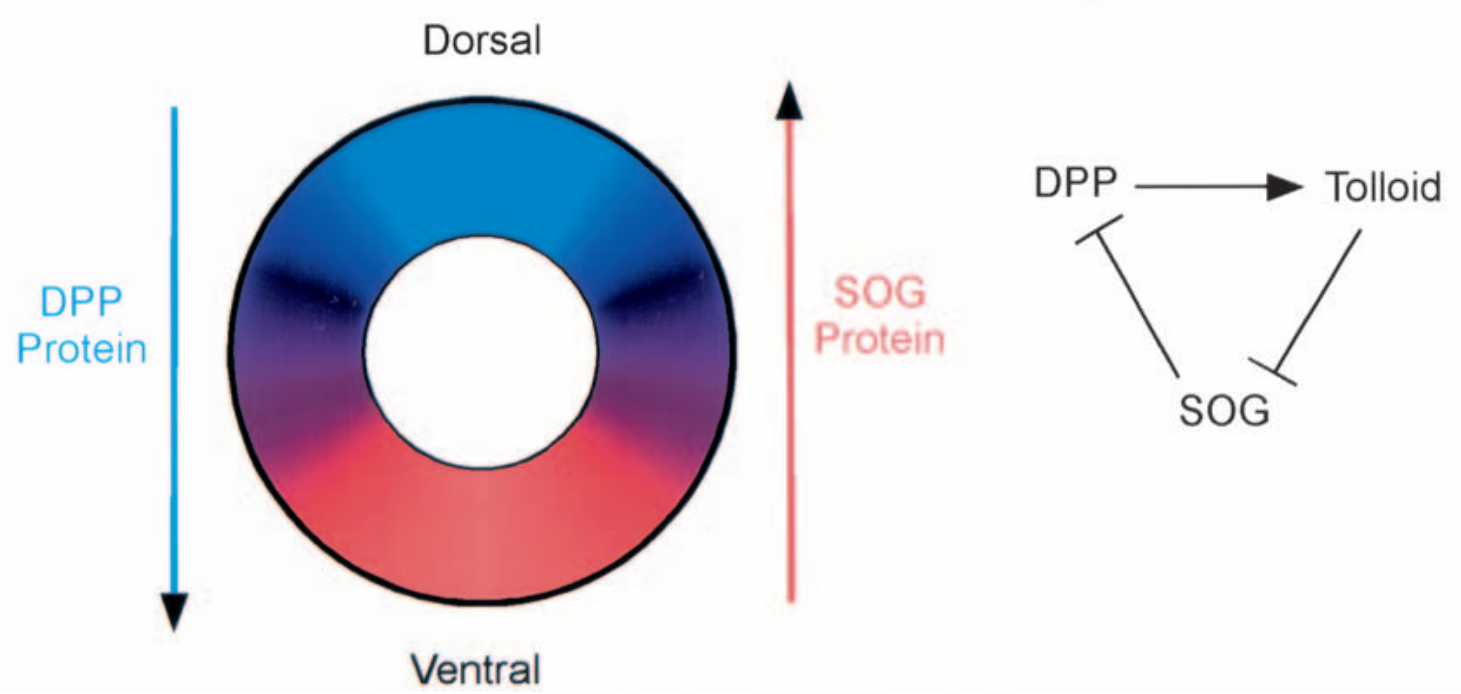

Figure 3. Regulation of TGF- $\beta$ signaling and gradient formation. $(A, B)$ After ligand binding, the heteromeric TGF- $\beta$ receptor complex (gray) is internalized into the endosome where it interacts with SMAD proteins. (A) Activation of signaling is mediated by the FYVE proteins SARA and Hrs, which recruit Smad2 to endosomes. Phosphorylation of Smad2 by the receptor complex leads to the disassociation of SARA and Hrs and the association of Smad4. The Smad2-Smad4 complex translocates to the nucleus to regulate transcription. (B) Inhibition of signaling is facilitated by the Smurf proteins through three possible mechanisms: (i) Smurf proteins traffic inhibitor Smad7 to the receptor complex where Smad7 prevents R-Smad association. (ii) Smurf proteins ubiquitinate the Smad7-receptor complex, resulting in receptor degradation. (iii) Smurf proteins ubiquitinate R-Smads Smad1 and Smad2, preventing signal transduction to the nucleus. $(C)$ DPP (blue) forms a DV gradient in the Drosophila embryo. DPP activity is negatively regulated by the SOG protein (red), which forms an inverse ventral-dorsal gradient. The combination of gradients forms an autoregulatory loop, which maintains both gradients. Dorsally, high levels of DPP activate Tolloid, which degrades SOG. The resultant low levels of SOG fail to inhibit DPP signaling. Conversely, ventrally, high levels of SOG inhibit DPP. Tolloid is not activated, which maintains high levels of SOG. 
teins to endosomes. SARA has been proposed to recruit Smad2 to the endosomal membrane where this SARASmad2 complex binds cooperatively to internalized TGF- $\beta$ receptor complexes (Fig. 3A). Notably, SARA mutants that mislocalize Smad2 result in inhibition of TGF- $\beta$ signaling, suggesting that this recruitment is important to signaling. Localization of Smad2 to endosomes may be facilitated by Hrs which, like SARA, contains an FYVE domain and can bind Smad2 (Miura et al. 2000). Recruitment of Smad2 to the internalized receptor complex is significantly increased in cells cotransfected with hrs and SARA compared to either gene alone, suggesting that Hrs and SARA cooperate to promote Smad2 activation at the endosome, thereby facilitating TGF- $\beta$ signaling.

\section{Morphogen gradients}

A recurring theme during development is the formation of gradients by morphogens, molecules that act in a concentration-dependent manner to specify cell fates. Morphogen gradients are capable of specifying multiple cell types out of a homogenous population of cells, a function frequently required during development. Despite the common occurrence of these gradients, the exact mechanisms through which they form and are maintained are still unclear (Gurdon and Bourillot 2001). Morphogen gradients are hypothesized to form by two mechanisms: diffusion and vesicle-mediated transport (Fig. 4; Strigini and Cohen 1999; Teleman et al. 2001). Diffusion is perhaps the more straightforward and widely favored hypothesis. Although free diffusion may account for the rapid formation of gradients over long distances found with some morphogens, restricted diffusion due to morphogen interactions with the extracellular matrix, lipid membranes, and membrane proteins may lead to slower gradient formation over shorter distances. Alternatively, vesicle-mediated transport of morphogens, also called planar transcytosis, is supported by the presence of morphogens in intracellular vesicles away from expressing cells. Furthermore, temperature sensitive mutations in the shibire gene encoding Dynamin, a protein required for vesicle internalization, can affect gradient range. Recently, the transcytosis model of gradient formation has garnered more attention as the links between morphogen signaling and endocytosis multiply. Finally, another recently proposed mechanism for gradient formation involves cellular processes that may directly release morphogens onto cells at various concentrations. However, these processes have only been proposed to transmit signals in a few contexts including the Drosophila imaginal disc and egg chamber (Ramirez-Weber and Kornberg 1999; Cho et al. 2000; Goode 2000; Gibson and Schubiger 2000). Regardless of the mechanism of morphogen gradient formation, there is mounting evidence that endocytosis regulates the concentration and range of morphogen activity by regulating not only the morphogen but also their downstream signaling members.

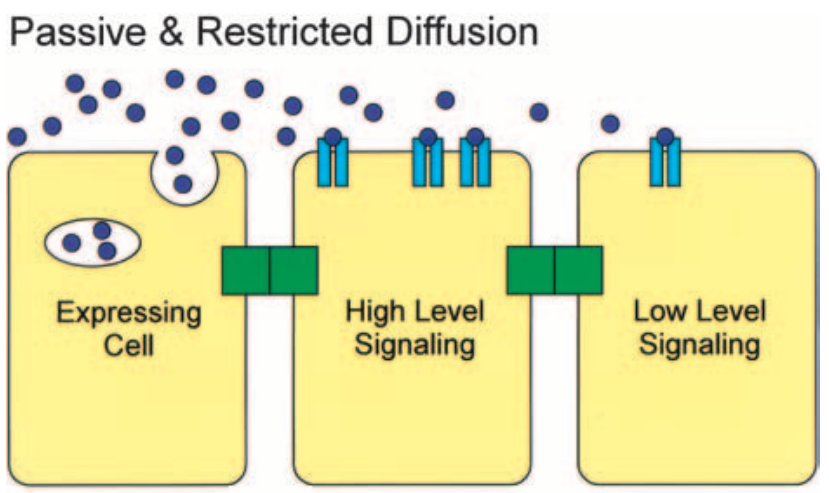

Vesicle-Mediated Transport

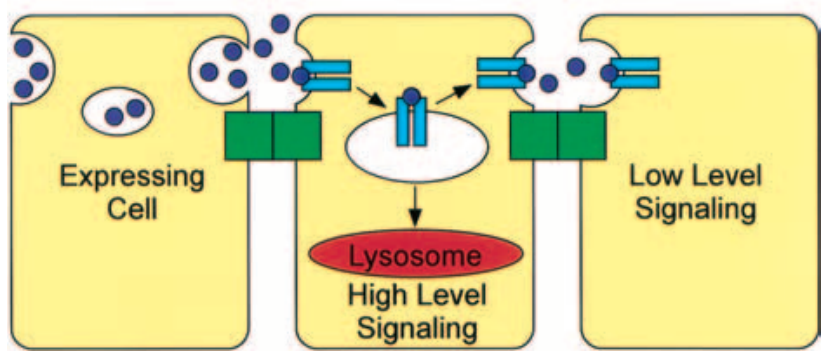

Figure 4. Models of morphogen gradient formation. The diffusion model of gradient formation proposes that a secreted morphogen is released from the expressing cell and diffuses away, creating a gradient with higher levels near the source. Diffusion may be passive leading to rapid gradient formation. Restricted diffusion attributable to morphogen interaction with extracellular matrix proteins, membrane proteins, or membrane lipids limits both the range and speed of gradient formation. The vesicle-mediated model of gradient formation, also called transcytosis, proposes that on release from the expressing cell, the morphogen is bound to membrane receptors on neighboring cells and is internalized. Once internalization has occurred, the morphogen can undergo degradation via the lysosome or be recycled to the membrane surface and released. Because of progressive degradation of the morphogen, cells further from the expressing cell are exposed to lower morphogen levels. This mechanism allows the formation of very steep or flat gradients by regulating the relative ratio of recycling to lysosomal degradation.

\section{Decapentaplegic gradient formation}

In addition to modulating TGF- $\beta$ signaling downstream of ligand binding, endocytosis may also regulate TGF- $\beta$ signaling by modulating gradient formation of the ligand itself. In the Drosophila wing disc, the TGF- $\beta$ homolog DPP forms a long range gradient near the anterior-posterior (AP) boundary that induces the expression of target genes spalt and optomotor-blind at different distances (Nellen et al. 1996). To investigate the mechanism of gradient formation, Entchev et al. (2000) constructed a DPP transgenic construct expressing GFP fused to the secretory domain of DPP that was unable to produce the mature DPP peptide. The fusion protein was expressed, secreted, and accumulated in the extracellular space of 
fly imaginal discs. However, unlike the full-length GFPtagged morphogen, the protein lacking the mature peptide did not form a gradient, demonstrating that the mature DPP peptide is required for gradient formation. Thus, DPP gradient formation is unlikely to occur by free diffusion alone.

Furthermore, Teleman and Cohen (2000) showed that DPP travels rapidly through tissue and is also rapidly degraded. DPP down-regulation may be mediated through the DPP receptor Thickveins, which colocalizes with the morphogen in an endocytic compartment. In thickveins mutant tissue, DPP accumulates in the extracellular space, suggesting that Thickveins mediates DPP internalization (Entchev et al. 2000). Thickveins is expressed in an inverse gradient to DPP with low levels at the AP boundary and high levels laterally (Lecuit and Cohen 1998). These high levels of Thickveins prevent DPP movement beyond the wing pouch. These data suggest that Thickveins-mediated internalization of DPP leads to signal degradation, creating a long-range gradient centered at the AP boundary. In addition, overexpression of Rab7, which promotes endosome to lysosome trafficking, results in a reduction of intracellular DPP and a reduced Spalt expression domain, consistent with reduced DPP range (Entchev et al. 2000). Therefore, the DPP gradient is modified by rapid down-regulation through Thickveins receptor-mediated internalization and lysosomal degradation.

Although Thickveins may be required for DPP downregulation, Thickveins may also facilitate morphogen spread. Within thickveins mutant clones, DPP accumulates extracellular to mutant cells (Entchev et al. 2000). However, beyond the mutant clone, no internalized DPP was observed, suggesting that DPP was unable to spread through the thickveins mutant clone. Thickveins may mediate morphogen spread by two possible mechanisms. Thickveins may carry or pass the morphogen across the cell surface (restricted diffusion). Alternatively, Thickveins may mediate DPP internalization and recycling to the surface (transcytosis). To distinguish between these possibilities, internalization was blocked and the effects on DPP gradient formation were analyzed (GonzalezGaitan and Jackle 1999; Entchev et al. 2000). shibire temperature-sensitive mutants show reduced DPP range. In addition, clathrin mutants and overexpression of dominant negative Rab5 both reduce the Spalt expression domain. These findings suggest that internalization drives the spread of DPP. Therefore, in the wing, Thickveins-mediated internalization regulates Decapentaplegic gradient formation in two ways, by mediating DPP lysosomal degradation and by facilitating morphogen spread via transcytosis.

In the Drosophila embryo, Decapentaplegic produces a morphogen gradient along the dorsal-ventral (DV) axis, defining multiple cell fates (Gelbart 1989; Arora et al. 1994; Morisato and Anderson 1995). In this case, DPP signaling may be regulated through Short gastrulation (SOG), the Drosophila homolog of the BMP inhibitor Chordin (Fig. 3C; Francois and Bier 1995). The secreted SOG protein forms a long-range inverse gradient to DPP with high levels ventrolaterally and low levels dorsally (Srinivasan et al. 2002). Ventrolaterally, high levels of SOG bind and inhibit DPP (Ferguson and Anderson 1992; Biehs et al. 1996). Dorsally, the low levels of SOG protein fail to inhibit DPP, allowing DPP to stimulate Tolloid, a secreted protein that cleaves dorsal SOG protein (Holley et al. 1996; Marques et al. 1997). As shown in Figure 3C, this DPP-stimulated inactivation of SOG produces a positive autoregulatory loop that upregulates DPP dorsally. Therefore, through antagonism of DPP signaling, the SOG gradient modulates the DPP gradient. Recent evidence has suggested that the gradient of SOG is also regulated by endocytosis (Srinivasan et al. 2002). In the wild type, dorsal levels of SOG are generally low, with higher levels near the ventral source. However, in shibire temperature-sensitive mutants, high levels of SOG are uniformly distributed in the dorsal region. Thus, dynamin-mediated internalization is required to down-regulate SOG dorsally. It could be argued that this effect is mediated through DPP-induced Tolloid degradation since internalization may affect DPP gradient formation in the wing. However, both shibire ${ }^{t s}, d p p$ and shibire $^{\text {ts }}$, tolloid double mutants showed greater increases in SOG protein levels dorsally than either mutation alone, suggesting that dynamin-mediated SOG degradation is independent of both DPP and Tolloid function. Thus, internalization and degradation are required to form the SOG gradient, which in turn regulates the DV DPP gradient in the Drosophila embryo.

\section{Hedgehog gradient formation}

Like DPP, Hedgehog is a highly conserved morphogen that functions in a variety of developmental contexts such as neural tube polarity and limb development. However, rather than being a freely secreted protein, mature Hedgehog is tethered to the plasma membrane through a covalently bonded cholesterol moiety (Lee et al. 1992; Porter et al. 1995, 1996; Burke et al. 1999). In Drosophila, the cholesterol modification localizes Hedgehog to lipid rafts within the membrane (Taylor et al. 1993; Rietveld et al. 1999). Although Hedgehog interacts with the plasma membrane through the transmembrane protein Dispatched, evidence suggests that Hedgehog can spread several cells away from its source (Marigo et al. 1996; Lewis et al. 2001; Zeng et al. 2001). Hedgehog mediates signaling through the transmembrane receptor Patched. In the absence of ligand, Patched inhibits the constitutively active transmembrane protein Smoothened through an unknown mechanism. Cell culture experiments suggest that Patched and Smoothened may form a complex (Stone et al. 1996; Murone et al. 1999; Karpen et al. 2001), although in vivo the proteins have not been shown to interact. Ligand binding to the Patched receptor releases this inhibition of Smoothened (Chen and Struhl 1996), and active Smoothened is able to stabilize Cubitus interruptus, which translocates to the nucleus and affects the transcription of target genes (Ingham and McMahon 2001). 
Given the limited understanding of the Hedgehog pathway as a whole, it is difficult to determine the endocytic regulation of signaling. There have been a few studies addressing the role of vesicle trafficking in Hedgehog regulation, however the data are suggestive at best and insufficient to draw a definite link between endocytosis and signaling. In this section, we will present some of the data on this topic and speculate as to possible mechanisms of protein action.

The mechanism through which Patched inhibits Smoothened has not been determined, however recent data suggests that Patched may act through regulation of Smoothened trafficking. At the membrane of cultured cells, Patched associates with Caveolin-1, leading to Patched and Smoothened localization to lipid rafts (Capdevila et al. 1994a,b; Karpen et al. 2001). In the Drosophila wing disc, Patched expression decreases Smoothened protein levels in the absence of ligand, suggesting that Patched may inhibit Smoothened activity by downregulating protein levels (Denef et al. 2000). Several mutants in Patched have shown that Smoothened downregulation is dependent on the Patched sterol-sensing domain (SSD) (Martin et al. 2001; Strutt et al. 2001). Although the mechanism of down-regulation has not been determined, the requirement for the sterol-sensing domain suggests that Patched may function by trafficking Smoothened through a membrane compartment (Ingham and McMahon 2001). The sterol-sensing domains of two other proteins have been implicated in the transport of proteins and lipids through membrane compartments. The SSD protein SCAP ( $\underline{\text { SREBP }}$ cleavage-acctivating protein) serves to shuttle SREBP (sterol regulatory element-binding protein) between the endoplasmic reticulum and Golgi (Nohturfft et al. 1999). A second SSD protein, Niemann Pick C1 protein, functions in the recycling of LDL cholesterol particles from the lysosome to the plasma membrane. Mutations in this protein result in toxic lipid accumulations within the cell (Brown and Goldstein 1983; Pentchev et al. 1985; Liscum and Faust 1987). Therefore, it is possible that the sterol-sensing domain of Patched mediates the trafficking of Smoothened through a membrane compartment, either by promoting its trafficking to the plasma membrane or by promoting its degradation via the lysosome.

Recent work has suggested that another vesicle-mediated process may be critical to the regulation of Hedgehog signaling (Eggenschwiler et al. 2001). Analysis of the mouse mutant open brain encoding a truncated form of Rab23 showed that, in the spinal cord, Rab23 functions downstream of ligand binding to negatively regulate Hedgehog signaling. The function of Rab23 has not been determined, but as a member of the Rab GTPase family, it is very likely to regulate vesicle trafficking events. These findings suggest that a component downstream of Hedgehog binding may be regulated by endocytosis.

In addition to regulating Hedgehog signaling, Patched also regulates the range of the Hedgehog gradient. Overexpression of the Patched receptor limits the range of the Hedgehog gradient (Nakano et al. 1989; Chen and Struhl 1996; Briscoe et al. 2001). This constriction of the mor- phogen gradient could be hypothesized to result from restricted diffusion or increased degradation after internalization. In support of the latter hypothesis, it was found that Patched undergoes dynamin-dependent internalization in the Drosophila embryo and can be localized to endocytic vesicles and multivesicular bodies (Capdevila et al. 1994a). Furthermore, Hedgehog binding to Patched stimulates internalization of the receptor and also stabilizes Smoothened at the plasma membrane (Denef et al. 2000). This stabilization of Smoothened protein may be due to posttranslational modification or a reduction in Patched-mediated degradation (Kalderon 2000). It is likely that Patched mediates Hedgehog internalization as Hedgehog and Patched colocalize to endocytic vesicles in a dynamin-dependent manner (Bellaiche et al. 1998; Burke et al. 1999; Incardona et al. 2000; Martin et al. 2001; Strutt et al. 2001). Hedgehog-Patched complexes travel to the lysosome of cultured cells, further suggesting that Patched-mediates Hedgehog degradation (Mastronardi et al. 2000). Hedgehog internalization and degradation are not dependent on the Patched sterol-sensing domain (Martin et al. 2001; Strutt et al. 2001). These findings suggest that Patched limits the Hedgehog gradient by internalizing Hedgehog in a dynamin-dependent manner and targeting the morphogen for lysosomal degradation. Furthermore, Patched may inhibit Hedgehog signaling by regulating Smoothened trafficking through membrane-bound compartments.

\section{Wnt/Wingless gradient formation}

Wnt and its Drosophila homolog Wingless are glycoproteins that form morphogen gradients that function in a variety of developmental processes. Although these signaling molecules are secreted, Wnt and Wingless bind tightly to glycosaminoglycans in the extracellular matrix (Bradley and Brown 1990; Reichsman et al. 1996), suggesting that gradient formation is unlikely to occur by free diffusion alone. Wnt and Wingless bind the seven transmembrane domain Frizzled family of receptors leading to phosphorylation of the PDZ domain protein Dishevelled. Via an as yet unclear mechanism, Dishevelled then prevents Glycogen synthase kinase 3 activity in the APC-Axin complex. Inhibition of this activity results in stabilized $\beta$-catenin/Armadillo protein which then enters the nucleus to regulate gene expression (Wodarz and Nusse 1998; Polakis 2000).

Forming the Wingless gradient In the Drosophila wing disc, Wingless forms a symmetric gradient spanning 5-10 cell diameters on each side of the DV boundary, while in the embryo, Wingless forms an asymmetric gradient located only anterior to the parasegment boundary (van den Heuvel et al. 1989). At the subcellular level, Wingless protein is present extracellularly abutting the plasma membrane and intracellularly in small vesicles and multivesicular bodies of nonexpressing cells, suggesting that Wg is readily internalized (van den Heuvel et al. 1989; Gonzalez et al. 1991; Strigini and Cohen 2000). 
Promoted by these findings, the relationship between endocytosis and Wingless gradient formation has been studied by observating membrane flow and genetically modulating the endocytic machinery.

Following the flow of membranes using fluorescently labeled glycophosphatidyl inositol showed that Drosophila wing disc cells secrete small labeled vesicles (called argosomes) that are capable of moving between cells (Greco et al. 2001). Argosomes are internalized and trafficked through the early endosome. Notably, Wingless appears to be associated with the membrane of argosomes through associations with heparin sulfate proteoglycans, and colocalizes with these vesicles structures in Wingless-receiving cells. These data suggest a vesicle-mediated mechanism of Wingless gradient formation in the wing.

Using shibire mutants to modulate endocytosis, Wingless gradient formation has been intensely investigated in both the embryo and wing disc. In temperature-sensitive shibire embryos at the restrictive temperature, the Wingless protein gradient was contracted to a narrow range around Wingless-expressing cells (Bejsovec and Wieschaus 1995). Based on these findings, Dynamin could be hypothesized to affect gradient formation through three possible mechanisms. First, Dynamin could promote Wingless secretion from expressing cells. However, in the shibire ${ }^{t s}$ embryo, Wingless protein was not detected in intracellular vesicles, unlike Wingless mutants known to be defective in secretion (Bejsovec and Wieschaus 1995; Dierick and Bejsovec 1998). Furthermore, the range of Wingless signaling has been analyzed by examining the Armadillo expression domain and the denticle pattern on the embryonic cuticle. Overexpression of dominant-negative shibire in Wingless-expressing cells showed that the range of Wingless signaling was not affected, signifying that Wingless is secreted and capable of signaling normally (Moline et al. 1999). Thus, it appears that Dynamin does not affect gradient formation by promoting Wingless secretion. Second, Dynamin could stabilize Wingless protein in nonexpressing cells. Although the effect of Dynamin on Wingless levels has not been analyzed directly in the embryo, studies of other endocytic mutants suggest that internalization does not stabilize Wingless protein levels. In fact, zygotic mutants in clathrin and deep orange (dor), which affect clathrin-mediated internalization and lysosomal degradation, respectively, enhanced the Wingless overexpression phenotype, suggesting that endocytosis down-regulates Wingless signaling (Dubois et al. 2001). Finally, it has been proposed that the narrowed Wingless gradient in the shibire ${ }^{t s}$ embryo is attributable to impaired morphogen spread. Supporting this, overexpression of dominant-negative shibire in a wide domain including the Wingless-expressing cells showed a contracted range of Wingless signaling, implicating Dynamin function in Wingless transport (Moline et al. 1999).

In the Drosophila wing imaginal disc, antibody staining of shibire mutant clones showed a similar restriction of Wingless protein to the area around Wingless-expressing cells (Fig. 5A,i; Strigini and Cohen 2000). Surpris- ingly however, a specialized staining protocol for extracellular protein, showed that within shibire mutant clones, extracellular Wingless was present around Wingless-nonexpressing cells (Fig. 5A,ii). This finding suggests that Wingless is able to spread to Wingless-nonexpressing cells in the absence of Dynamin. Furthermore, extracellular Wingless was present at higher levels within the shibire mutant clone than outside the clone, suggesting that Dynamin serves to down-regulate morphogen levels. Reconciling the extracellular and conventional staining data, Strigini and Cohen (2000) propose that the restricted Wingless pattern in shibire mutant clones is attributable to a failure to secrete Wingless. Given the conflicting conclusions drawn from the embryo and wing disc data, it is possible that the mechanisms of gradient formation differ between these two tissues. Clearly, more investigation is needed to determine what role Dynamin and endocytosis play in forming the Wingless gradient.

Modifying the gradient: creating gradient asymmetry Before embryonic stage 10, the Wingless gradient in the Drosophila embryo is symmetric around the parasegment boundary, defining the width of engrailed expression. However, by stage 11 , the Wingless gradient becomes asymmetric and is restricted anterior of the parasegment boundary. Recently, evidence has suggested that endocytosis may serve to regulate the creation of this asymmetry by altering levels of degradation. In order to follow Wingless movement and degradation, a horseradish peroxidase (HRP)-Wingless fusion protein was expressed under the control of the Wingless promoter. Since the HRP moiety is relatively stably throughout the endocytic pathway, including the lysosome, it is possible to monitor Wingless degradation in vivo. In Winglessnonexpressing cells posterior to the parasegment boundary, Wingless staining is not detected while HRP staining is largely localized to multivesicular bodies and lysosomes, suggesting that the HRP-Wingless fusion moves through the endocytic pathway and Wingless is degraded in these cells (Dubois et al. 2001). HRP staining is noted beyond the Wingless protein gradient, again providing evidence that degradation limits gradient range. Furthermore, four times more MVBs and lysosomes labeled with HRP were observed in the posterior segment than the anterior segment, implying that increased Wingless degradation posteriorly may result in gradient asymmetry.

Hedgehog signaling has been shown to prevent the Wingless gradient from extending posteriorly (Fig. 5B; Sanson et al. 1999). One target of Hedgehog signaling is rhomboid. Rhomboid mutants show increased vesicular Wingless staining in the posterior compartment, suggesting that Rhomboid is required for Wingless degradation posteriorly (Dubois et al. 2001). Notably, Rhomboid activates the EGFR ligand Spitz (Schweitzer et al. 1995; Urban et al. 2001; Tsruya et al. 2002), and EGFR mutants also show increased posterior Wingless staining (Dubois et al. 2001). Therefore, Hedgehog and EGFR signaling limit the Wingless gradient by upregulating Wingless 
A

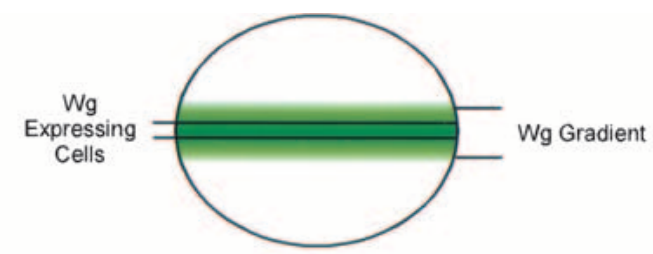

(i)

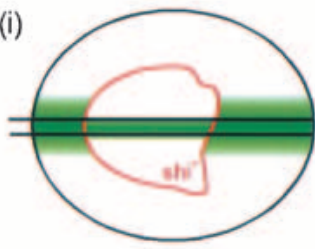

Conventional Staining

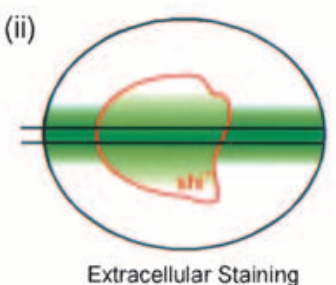

Extracellular Staining

B

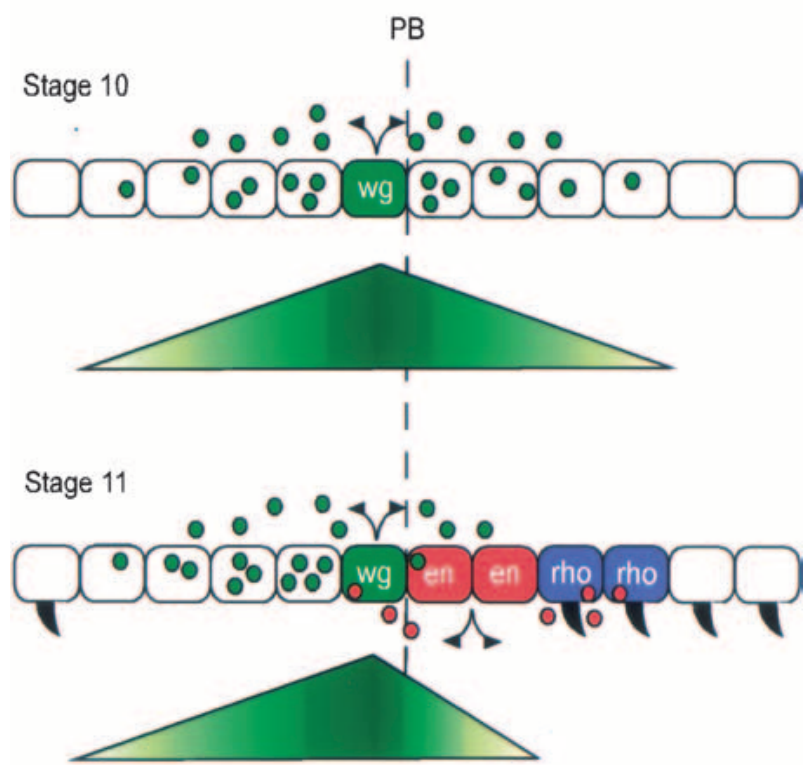

Figure 5. Wingless gradients in Drosophila. (A) In the wing pouch, Wingless protein (green) is expressed by cells at the dorsalventral boundary and spreads symmetrically. Wingless can be detected intracellularly in both expressing and receiving cells within the gradient. Analysis of shibire mutant clones (outlined in red) produced data about the role of Dynamin in Wingless gradient formation: (i) Conventional staining for internalized protein shows less staining in receiving cells and intense staining in expressing cells, suggesting a role in morphogen secretion or transport. (ii) An extracellular staining protocol for extracellular Wingless shows increased extracellular protein around receiving cells, suggesting that transport is not affected. $(B)$ In the embryo, the Wingless protein (green circles) is initially symmetrically distributed around the expressing cell (green cell) at the parasegment boundary $(\mathrm{PB})$ and defines the range of engrailed expression. By stage 11, the Engrailed-expressing cells (red cell) secrete Hedgehog (red circles), which modifies the Wingless gradient. Posteriorly, Hedghog induces Rhomboid expression (purple cells), which activates the EGFR ligand Spitz. Hedgehog and EGF signaling upregulate lysosomal degradation of Wingless posterior to the parasegment boundary. Anteriorly, Hedgehog acts to up-regulate Wingless expression, thereby increasing the range. Overall, this produces an asymmetric Wingless gradient where Wingless signaling anterior to the parasegment boundary induces a naked cuticle and denticles develop posteriorly.

degradation. Thus, signaling pathways may interact with other pathways by regulating the endocytosis of signaling members.

\section{Notch signaling}

Notch signaling has been implicated in a variety of developmental functions including regulation of cell proliferation and cell fate determination. In the nervous system, the Notch pathway mediates the selection of a single neuroblast from a proneural cluster of equivalent cells through a process known as lateral inhibition (Beatus and Lendahl 1998). In this model, slight imbalances in Notch signaling are amplified such that the signaling cell develops into a neuroblast and prevents the surrounding ectodermal cells from choosing a similar fate. These intercellular interactions are mediated through Notch/LIN-12, a conserved transmembrane receptor. To activate Notch, transmembrane proteins of the DSL family (Delta, Serrate, Lag-2) bind to the Notch receptor, allowing Kuzbanian to cleave Notch extracellularly (Pan and Rubin 1997; Lieber et al. 2002). This extracellular cleavage permits Presenilin proteins to cleave Notch intracellularly near the transmembrane domain (De Strooper et al. 1999; Struhl and Greenwald 1999; Ye et al. 1999). Although immunocytochemical detection of the Notch intracellular fragment has been unsuccessful, work by Struhl and Adachi (1998) indicates that the Notch intracellular domain translocates to the nucleus where its interaction with Suppressor of Hairless/RBP- $\mathrm{J}_{\mathrm{K}}$ activates the transcription of downstream genes. Notch signaling is extensively regulated through intracellular associations with positive regulators like Deltex and Suppressor of Hairless and negative regulators like Numb, Hairless, and Suppressor of Deltex (Panin and Irvine 1998; Artavanis-Tsakonas et al. 1999).

\section{Activation of Notch signaling}

Recent evidence suggests that endocytosis may play a critical role in the activation of Notch signaling, a novel and distinct mechanism of endocytic signaling regulation (Fig. 6). Delta is localized both at the cell surface and in endocytic vesicles, including MVBs (Parks et al. 1995). Antibody stainings show that Notch colocalizes with Delta in some of these vesicles, suggesting that NotchDelta complexes may be internalized into the signaling cell (Kooh et al. 1993). In cell culture experiments, this internalization of Delta correlates with signaling activity (Fehon et al. 1990). In vivo, shibire mutants phenocopy the Notch loss of function neurogenic phenotype, suggesting that internalization is required for Notch signaling (Poodry 1990). Subsequent epistasis studies and clonal analysis using temperature-sensitive shibire mutants revealed that Dynamin is required autonomously for Notch activation in both the signaling and receiving cells (Seugnet et al. 1997). Recent cell culture and in vivo analyses have shed light on the requirement of Dynamin in the signal-sending cells, but the role of Dynamin in 


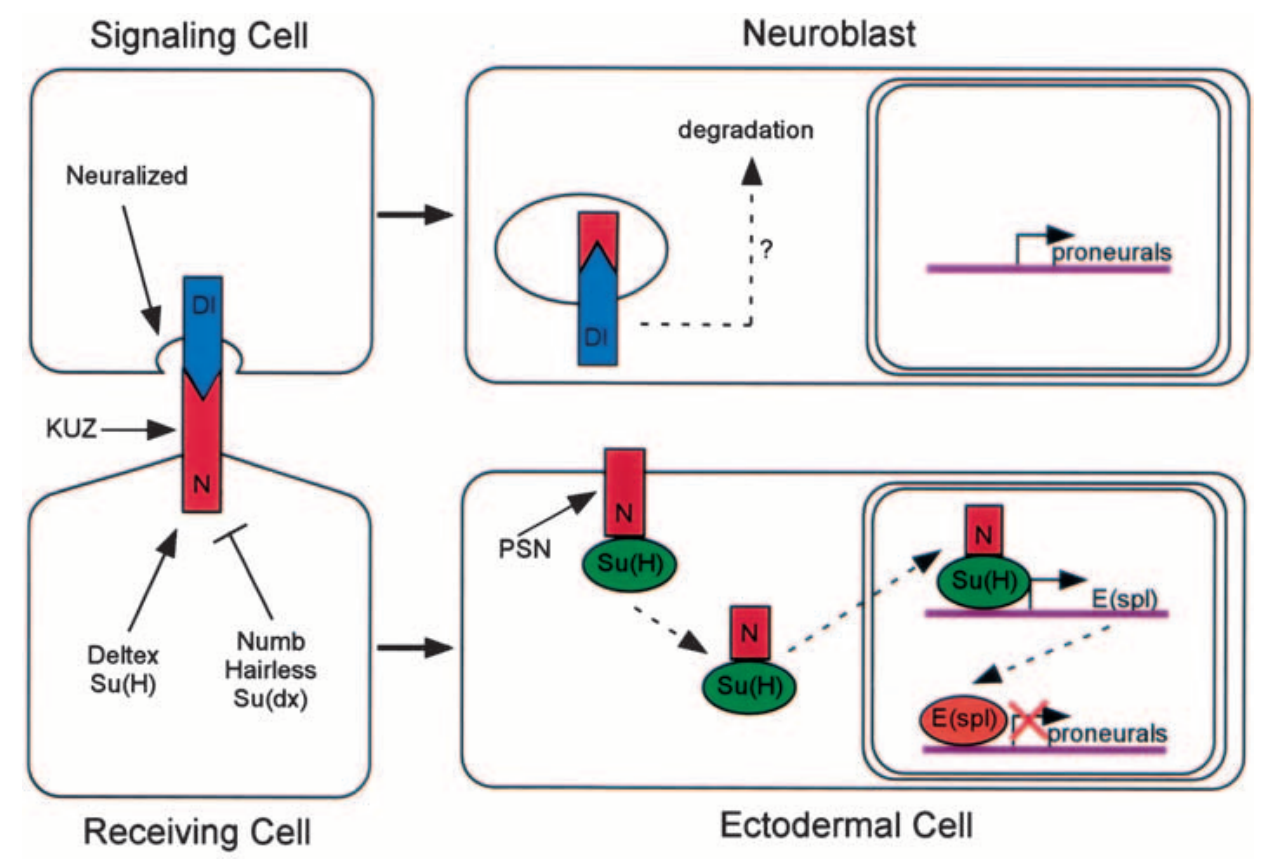

Figure 6. Activation of Notch signaling. On ligand binding, the Notch-Delta complex undergoes internalization, possibly due to neuralized-mediated monoubiquitination of Delta. Internalization into the signaling cell facilitates the extracellular cleavage of Notch by Kuzbanian (KUZ). Once internalized, the Notch ${ }^{\mathrm{ECD}}$-Delta complex undergoes proteosome-mediated or lysosomal degradation. The lack of Notch signaling in the signaling cell allows the expression of proneural genes, which specify a neural fate. In the receiving cell, extracellular Notch cleavage promotes Presenilin (PSN) cleavage of Notch in the juxtamembrane region, allowing the Notch ${ }^{\mathrm{ICD}}-$ Suppressor of Hairless $[\mathrm{Su}(\mathrm{H})]$ complex to enter the nucleus and up-regulate the transcription of downstream genes like the enhancer of split complex. Enhancer of Split inhibits the expression of the proneural genes, resulting in an ectodermal fate. Signaling activity in the receiving cell is extensively modulated by intracellular proteins such as Deltex, Numb, Hairless, and Suppressor of Deltex $[\mathrm{Su}(\mathrm{dx})]$.

the receiving cell remains to be determined. In the Deltaexpressing cell, the Notch extracellular domain $\left(\mathrm{N}^{\mathrm{ECD}}\right)$ binds to Delta and the complex undergoes dynamin-dependent internalization (Parks et al. 2000). This internalization of $\mathrm{N}^{\mathrm{ECD}}$ appears to promote the separation of the Notch intracellular domain $\left(\mathrm{N}^{\mathrm{ICD}}\right)$, possibly by facilitating extracellular Notch cleavage by Kuzbanian. Thus, dynamin-dependent internalization of $\mathrm{N}^{\mathrm{ECD}}$ into the signaling cell is required for Notch signaling. Interestingly, in the absence of shibire, $\mathrm{N}^{\mathrm{ECD}}$ and $\mathrm{N}^{\mathrm{ICD}}$ can be internalized together with Delta in signaling cells of the wing disc, suggesting that a dynamin-independent internalization mechanism may also exist. Furthermore, it has been suggested that, at least in vitro, Notch and Delta can cell autonomously form homomeric and heteromeric complexes that repress Notch signaling, adding an additional dimension of complexity to signal regulation (Sakamoto et al. 2002). Although more work is needed to clarify this process further, it appears that, in the signaling cell, $\mathrm{N}^{\mathrm{ECD}}$ Delta complex internalization is required for the activation of Notch signaling.

A potential mechanism for the internalization of $\mathrm{N}^{\mathrm{ECD}}$ Delta complexes has been recently proposed based on analyses of the E3 ubiquitin ligase Neuralized. Neuralized was initially isolated as a neurogenic gene that when mutated phenocopies Notch loss of function mutations (Yeh et al. 2000). Neuralized appears to be re- quired in multiple Notch-regulated processes such as lateral inhibition in peripheral neurogenesis and asymmetric cell division in sensory organ development (Yeh et al. 2000; Lai et al. 2001). The presence of a RING domain, a motif common to ubiquitin ligases, raises the possibility that Neuralized may positively regulate Notch signaling through ubiquitination of signaling members (Yeh et al. 2000). Recent work in Drosophila and Xenopus has shown that Neuralized binds and ubiquitinates Delta and stimulates Delta internalization. Although Neuralized mutants show surface accumulation of Delta, overexpression of Neuralized results in rapid Delta degradation (Deblandre et al. 2001; Lai et al. 2001; Pavlopoulos et al. 2001). Furthermore, neuralized-mediated internalization and degradation of Delta are dependent on the Neuralized RING domain. In vitro, ubiquitination of Delta could target Delta for proteosome-mediated or lysosomal degradation (Lai et al. 2001; Pavlopoulos et al. 2001). Notably, Deblandre et al. (2001) showed that in Xenopus Delta is monoubiquitinated, which may serve as a signal for internalization and lysosomal degradation. Thus, Neuralized promotes Notch signaling by monoubiquitinating Delta, likely targeting it for internalization and degradation. Interestingly, Neuralized has been shown to affect Notch activity both cell autonomously and nonautonomously, suggesting that it may function by two mechanisms (Kramer 2001). First, Neuralized 
could down-regulate Delta, preventing the formation of intracellular Notch-Delta complexes that repress Notch signaling cell autonomously. Second, by stimulating internalization of Delta and the Notch extracellular domain, Neuralized could promote $\mathrm{N}^{\mathrm{ICD}}$ separation and signaling in a nonautonomous manner. In either case, it is clear that endocytosis may regulate Notch signaling at multiple levels, affecting the degradation of Notch and Delta and the activation of Notch signaling.

\section{Down-regulation of Notch signaling}

In addition to activating Notch signaling, several pieces of evidence suggest that Notch receptors may also undergo endocytosis-dependent down-regulation. Numb, a phosphotyrosine-binding domain protein, is asymmetrically segregated during the division of sensory organ precursor cells and serves to determine cell fate through its inhibition of Notch (Guo et al. 1996; Zhong et al. 1996). In cell culture, Numb binds directly to Notch and interferes with Notch-mediated nuclear translocation of Suppressor of Hairless (Frise et al. 1996). Recently, it was found that Numb may act as an endocytic protein (Santolini et al. 2000). On growth factor stimulation, the Numb protein has been shown to be redistributed to the cell surface where it localizes to clathrin-coated pits through its interactions with $\alpha$-adaptin. On the cell surface, Numb can associate with receptors like EGFR, and the complex is internalized into an endosomal compartment. Numb binds Eps15 and colocalizes with Eps15 on endosomes. Overexpression of a Numb fragment that does not associate with $\alpha$-adaptin or Eps15 acts in a dominant negative manner, preventing internalization of EGFR. This suggests that Numb plays a critical role in the internalization of cell surface receptors through its interactions with $\alpha$-adaptin and Eps15. Given that Numb binds to and negatively regulates Notch, it is possible that Numb attenuates Notch signaling by downregulating Notch through an endocytic mechanism.

Suppressor of Deltex is another intracellular negative regulator of Notch signaling that suggests that endocytosis may regulate Notch signaling. As its name implies, Suppressor of deltex suppresses mutations in Deltex, a cytoplasmic protein that binds to Notch (Xu and Artavanis-Tsakonas 1990; Diederich et al. 1994). Suppressor of deltex interacts with a variety of Notch signaling mutants and genetically plays an inhibitory role in Notch signaling (Fostier et al. 1998; Cornell et al. 1999). Notably, the Suppressor of Deltex domain structure places it within the Nedd4/Rsp5p family of E3 ubiquitin ligase proteins which mono- and polyubiquitinate plasma membrane proteins (Rotin et al. 2000). In human Jurkat cells, the mouse homolog of Suppressor of Deltex, Itch, appears to bind to the intracellular domain of Notch, leading to mono- and polyubquitination of Notch. Qiu et al. (2000) propose that ubiquitinated Notch undergoes proteosome-mediated degradation. However, given that monoubquitinated forms are evident, Itch may mediate Notch internalization or sorting into multivesicular bodies for lysosomal degradation. Furthermore, studies of the E3 ubiquitin ligase c-Cbl in myoblast cells suggest that $\mathrm{c}-\mathrm{Cbl}$ mediates monoubiquitination of Notch targeting Notch for lysosomal degradation (Jehn et al. 2002). Therefore, although evidence for the ubiquitination of Notch leading to internalization and possibly lysosomal degradation is limited, it is suggestive and warrants further investigation.

\section{Conclusion}

Vesicle trafficking and developmental signaling have been predominantly studied independently. However, there is mounting evidence that developmental signaling can be regulated by endocytosis in multiple ways. First, endocytosis can serve to modulate signaling. Signaling can be regulated through lysosomal degradation of receptors and other pathway members. In TGF- $\beta$ signaling, receptor internalization may affect signaling by facilitating associations with Smad proteins at the endosome. The receptor and Smad proteins may also undergo lysosomal degradation. Second, endocytosis likely plays a role in morphogen gradient formation. In Decapentaplegic, Hedgehog, and Wingless signaling, receptor-mediated internalization may lead to lysosomal degradation of the morphogen. This degradation may limit the gradient in a directional manner, as was noted in the asymmetric Wingless gradient of the Drosophila embryo. Furthermore, analysis of shibire mutants has suggested that endocytosis is important for the spread of Decapentaplegic and Wingless. These findings support the model that, after internalization, the morphogen-receptor complex may be degraded via the lysosome or recycled to the cell surface for further spread. By altering the relative ratio of recycling to lysosomal degradation, the concentration and range of the morphogen can be controlled. Finally, findings in Notch suggest that endocytosis may be critical to activation of signaling. Internalization of the Delta- $\mathrm{N}^{\mathrm{ECD}}$ complex into the signaling cell facilitates the release of the Notch intracellular domain, thereby allowing signaling to occur.

Although evidence suggests an important role for endocytosis in the regulation of developmental signaling, studies have rarely made use of the numerous proteins known to be involved in vesicle trafficking. Several studies have examined the effects of altered Dynamin activity on signaling, however, only recently have the effects of other vesicle trafficking proteins like the Rab proteins and Hrs been investigated (Entchev et al. 2000; Lloyd et al. 2002). These trafficking proteins will likely prove to be valuable tools in the elucidation of signaling regulation and morphogen gradient formation. In addition, ubiquitination, which has largely been assumed to target proteins to the proteosome, may regulate signaling through endocytosis. E3 ubiquitin ligases are involved in several signaling pathways and have been shown to target signaling proteins for internalization and lysosomal degradation. Furthermore, signaling pathways like EGFR have been shown to directly regulate the endocytic machinery, thereby allowing signaling pathways to modulate themselves and to interact with other pathways. For 
example, Hedgehog signaling in the posterior compartment of the Drosophila embryo may limit the Wingless gradient by up-regulating Wingless internalization and lysosomal degradation in a site-specific manner. Clearly, we have only just begun to understand the role that endocytosis plays in regulating signaling and further investigation will likely provide new insights into the signaling pathways that function during development.

\section{References}

Anders, R.A. and Leof, E.B. 1996. Chimeric granulocyte/macrophage colony-stimulating factor/transforming growth factor- $\beta$ (TGF- $\beta$ ) receptors define a model system for investigating the role of homomeric and heteromeric receptors in TGF- $\beta$ signaling. J. Biol. Chem. 271: 21758-21766.

Anders, R.A., Arline, S.L., Dore, J.J., and Leof, E.B. 1997. Distinct endocytic responses of heteromeric and homomeric transforming growth factor $\beta$ receptors. Mol. Biol. Cell 8: 2133-2143.

Anders, R.A., Dore, Jr., J.J., Arline, S.L., Garamszegi, N., and Leof, E.B. 1998. Differential requirement for type I and type II transforming growth factor $\beta$ receptor kinase activity in ligand-mediated receptor endocytosis. J. Biol. Chem. 273: 23118-23125.

Arora, K., Levine, M.S., and O'Connor, M.B. 1994. The screw gene encodes a ubiquitously expressed member of the TGF- $\beta$ family required for specification of dorsal cell fates in the Drosophila embryo. Genes \& Dev. 8: 2588-2601.

Artavanis-Tsakonas, S., Rand, M.D., and Lake, R.J. 1999. Notch signaling: Cell fate control and signal integration in development. Science 284: 770-776.

Asao, H., Sasaki, Y., Arita, T., Tanaka, N., Endo, K., Kasai, H., Takeshita, T., Endo, Y., Fujita, T., and Sugamura, K. 1997. Hrs is associated with STAM, a signal-transducing adaptor molecule. Its suppressive effect on cytokine-induced cell growth. J. Biol. Chem. 272: 32785-32791.

Babst, M., Odorizzi, G., Estepa, E.J., and Emr, S.D. 2000. Mammalian tumor susceptibility gene 101 (TSG101) and the yeast homologue, Vps23p, both function in late endosomal trafficking. Traffic 1: 248-258.

Bankaitis, V.A., Johnson, L.M., and Emr, S.D. 1986. Isolation of yeast mutants defective in protein targeting to the vacuole. Proc. Natl. Acad. Sci. 83: 9075-9079.

Beatus, P. and Lendahl, U. 1998. Notch and neurogenesis. I. Neurosci. Res. 54: 125-136.

Bejsovec, A. and Wieschaus, E. 1995. Signaling activities of the Drosophila wingless gene are separately mutable and appear to be transduced at the cell surface. Genetics 139: 309-320.

Bellaiche, Y., The, I., and Perrimon, N. 1998. Tout-velu is a Drosophila homologue of the putative tumour suppressor EXT-1 and is needed for Hh diffusion. Nature 394: 85-88.

Benmerah, A., Lamaze, C., Begue, B., Schmid, S.L., Dautry-Varsat, A., and Cerf-Bensussan, N. 1998. AP-2/Eps15 interaction is required for receptor-mediated endocytosis. J. Cell Biol. 140: 1055-1062.

Biehs, B., Francois, V., and Bier, E. 1996. The Drosophila short gastrulation gene prevents Dpp from autoactivating and suppressing neurogenesis in the neuroectoderm. Genes \& Dev. 10: $2922-2934$.

Bradley, R.S. and Brown, A.M. 1990. The proto-oncogene int-1 encodes a secreted protein associated with the extracellular matrix. EMBO J. 9: 1569-1575.

Briscoe, J., Chen, Y., Jessell, T.M., and Struhl, G. 2001. A hedgehog-insensitive form of Patched provides evidence for direct long-range morphogen activity of sonic hedgehog in the neural tube. Mol. Cell 7: 1279-1291.

Brodsky, F.M., Chen, C.Y., Kneuhl, C., Towler, M.C., and Wakeham, D.E. 2001. Biological basket weaving: Formation and function of clathrin-coated vesicles. Annu. Rev. Cell. Dev. Biol. 17: 517-568.

Brown, M.S. and Goldstein, J.L. 1983. Lipoprotein receptors in the liver. Control signals for plasma cholesterol traffic. $J$. Clin. Invest. 72: 743-747.

Bucci, C., Parton, R.G., Mather, I.H., Stunnenberg, H., Simons, K., Hoflack, B., and Zerial, M. 1992. The small GTPase Rab5 functions as a regulatory factor in the early endocytic pathway. Cell 70: 715-728.

Burke, P., Schooler, K., and Wiley, H.S. 2001. Regulation of epidermal growth factor receptor signaling by endocytosis and intracellular trafficking. Mol. Biol. Cell 12: 1897-1910.

Burke, R., Nellen, D., Bellotto, M., Hafen, E., Senti, K.A., Dickson, B.J., and Basler, K. 1999. Dispatched, a novel sterolsensing domain protein dedicated to the release of cholesterol-modified Hedgehog from signaling cells. Cell 99: 803815

Capdevila, J., Estrada, M.P., Sanchez-Herrero, E., and Guerrero, I. 1994a. The Drosophila segment polarity gene patched interacts with Decapentaplegic in wing development. EMBO J. 13: $71-82$.

Capdevila, J., Pariente, F., Sampedro, J., Alonso, J.L., and Guerrero, I. 1994b. Subcellular localization of the segment polarity protein Patched suggests an interaction with the Wingless reception complex in Drosophila embryos. Development 120: 987-998.

Carbone, R., Fre, S., Iannolo, G., Belleudi, F., Mancini, P., Pelicci, P.G., Torrisi, M.R., and Di Fiore, P.P. 1997. Eps15 and Eps15R are essential components of the endocytic pathway. Cancer Res. 57: 5498-5504.

Caron, E. and Hall, A. 2001. Phagocytosis. In Frontiers in molecular biology (ed. M. Marsh), pp. 58-77. Oxford University Press, New York, NY.

Ceresa, B.P., Lotscher, M., and Schmid, S.L. 2001. Receptor and membrane recycling can occur with unaltered efficiency despite dramatic Rab5(q791)-induced changes in endosome geometry. J. Biol. Chem. 276: 9649-9654.

Chavrier, P., Parton, R.G., Hauri, H.P., Simons, K., and Zerial, M. 1990. Localization of low molecular weight GTP binding proteins to exocytic and endocytic compartments. Cell 62: 317-329.

Chen, H., Fre, S., Slepnev, V.I., Capua, M.R., Takei, K., Butler, M.H., Di Fiore, P.P., and De Camilli, P. 1998. Epsin is an EH-domain-binding protein implicated in clathrin-mediated endocytosis. Nature 394: 793-797.

Chen, R.H., Ebner, R., and Derynck, R. 1993. Inactivation of the type II receptor reveals two receptor pathways for the diverse TGF- $\beta$ activities. Science 260: 1335-1338.

Chen, W.S., Lazar, C.S., Lund, K.A., Welsh, J.B., Chang, C.P. Walton, G.M., Der, C.J., Wiley, H.S., Gill, G.N., and Rosenfeld, M.G. 1989. Functional independence of the epidermal growth factor receptor from a domain required for ligandinduced internalization and calcium regulation. Cell 59: 3343.

Chen, Y. and Struhl, G. 1996. Dual roles for Patched in sequestering and transducing Hedgehog. Cell 87: 553-563.

Cho, K.O., Chern, J., Izaddoost, S., and Choi, K.W. 2000. Novel signaling from the peripodial membrane is essential for eye disc patterning in Drosophila. Cell 103: 331-342.

Christoforidis, S., McBride, H.M., Burgoyne, R.D., and Zerial, M. 1999a. The Rab5 effector EEA1 is a core component of endosome docking. Nature 397: 621-625. 
Christoforidis, S., Miaczynska, M., Ashman, K., Wilm, M., Zhao, L., Yip, S.C., Waterfield, M.D., Backer, J.M., and Zerial, M. 1999b. Phosphatidylinositol-3-OH kinases are Rab5 effectors. Nat. Cell Biol. 1: 249-252.

Cohen, S. and Fava, R.A. 1985. Internalization of functional epidermal growth factor: receptor/kinase complexes in A-431 cells. J. Biol. Chem. 260: 12351-12358.

Confalonieri, S., Salcini, A.E., Puri, C., Tacchetti, C., and Di Fiore, P.P. 2000. Tyrosine phosphorylation of Eps15 is required for ligand-regulated, but not constitutive, endocytosis. J. Cell Biol. 150: 905-912.

Cornell, M., Evans, D.A., Mann, R., Fostier, M., Flasza, M., Monthatong, M., Artavanis-Tsakonas, S., and Baron, M. 1999. The Drosophila melanogaster Suppressor of deltex gene, a regulator of the Notch receptor signaling pathway, is an E3 class ubiquitin ligase. Genetics 152: 567-576.

Cowles, C.R., Odorizzi, G., Payne, G.S., and Emr, S.D. 1997. The AP-3 adaptor complex is essential for cargo-selective transport to the yeast vacuole. Cell 91: 109-118.

Cremona, O., Di Paolo, G., Wenk, M.R., Luthi, A., Kim, W.T., Takei, K., Daniell, L., Nemoto, Y., Shears, S.B., Flavell, R.A., et al. 1999. Essential role of phosphoinositide metabolism in synaptic vesicle recycling. Cell 99: 179-188.

Cupers, P., ter Haar, E., Boll, W., and Kirchhausen, T. 1997. Parallel dimers and anti-parallel tetramers formed by epidermal growth factor receptor pathway substrate clone 15 . $J$. Biol. Chem. 272: 33430-33434.

Dautry-Varsat, A. 2001. Clathrin-independent endocytosis. Oxford University Press, New York, NY.

Deblandre, G.A., Lai, E.C., and Kintner, C. 2001. Xenopus neuralized is a ubiquitin ligase that interacts with XDelta1 and regulates Notch signaling. Dev. Cell 1: 795-806.

Denef, N., Neubuser, D., Perez, L., and Cohen, S.M. 2000. Hedgehog induces opposite changes in turnover and subcellular localization of Patched and Smoothened. Cell 102: 521-531.

Derynck, R., Akhurst, R.J., and Balmain, A. 2001. TGF- $\beta$ signaling in tumor suppression and cancer progression. Nat. Genet. 29: 117-129.

De Strooper, B., Annaert, W., Cupers, P., Saftig, P., Craessaerts, K., Mumm, J.S., Schroeter, E.H., Schrijvers, V., Wolfe, M.S., Ray, W.J., et al. 1999. A Presenilin-1-dependent $\gamma$-secretaselike protease mediates release of Notch intracellular domain. Nature 398: 518-522.

Di Fiore, P.P. and De Camilli, P. 2001. Endocytosis and signaling: An inseparable partnership. Cell 106: $1-4$.

Diederich, R.J., Matsuno, K., Hing, H., and Artavanis-Tsakonas, S. 1994. Cytosolic interaction between Deltex and Notch ankyrin repeats implicates Deltex in the Notch signaling pathway. Development 120: 473-481.

Dierick, H.A. and Bejsovec, A. 1998. Functional analysis of Wingless reveals a link between intercellular ligand transport and dorsal-cell-specific signaling. Development 125: 4729-4738.

Dietrich, J., Hou, X., Wegener, A.M., and Geisler, C. 1994. CD3 gamma contains a phosphoserine-dependent di-leucine motif involved in down-regulation of the T cell receptor. EMBO J. 13: 2156-2166.

DiGuglielmo, G.M., Baass, P.C., Ou, W.J., Posner, B.I., and Bergeron, J.J. 1994. Compartmentalization of SHC, GRB2 and mSOS, and hyperphosphorylation of Raf-1 by EGF but not insulin in liver parenchyma. EMBO J. 13: 4269-4277.

Dittrich, E., Haft, C.R., Muys, L., Heinrich, P.C., and Graeve, L. 1996. A di-leucine motif and an upstream serine in the interleukin-6 (IL-6) signal transducer gp130 mediate ligandinduced endocytosis and down-regulation of the IL- 6 recep- tor. J. Biol. Chem. 271: 5487-5494.

Dore, Jr., J.J., Edens, M., Garamszegi, N., and Leof, E.B. 1998. Heteromeric and homomeric transforming growth factor- $\beta$ receptors show distinct signaling and endocytic responses in epithelial cells. J. Biol. Chem. 273: 31770-31777.

Dore, Jr., J.J., Yao, D., Edens, M., Garamszegi, N., Sholl, E.L., and Leof, E.B. 2001. Mechanisms of transforming growth factor- $\beta$ receptor endocytosis and intracellular sorting differ between fibroblasts and epithelial cells. Mol. Biol. Cell 12: 675-684.

Dubois, L., Lecourtois, M., Alexandre, C., Hirst, E., and Vincent, J.P. 2001. Regulated endocytic routing modulates Wingless signaling in Drosophila embryos. Cell 105: 613-624.

Ebisawa, T., Fukuchi, M., Murakami, G., Chiba, T., Tanaka, K., Imamura, T., and Miyazono, K. 2001. Smurf1 interacts with transforming growth factor- $\beta$ type I receptor through Smad7 and induces receptor degradation. J. Biol. Chem. 276: 1247712480.

Eggenschwiler, J.T., Espinoza, E., and Anderson, K.V. 2001. Rab23 is an essential negative regulator of the mouse Sonic hedgehog signalling pathway. Nature 412: 194-198.

Ehrlich, M., Shmuely, A., and Henis, Y.I. 2001. A single internalization signal from the di-leucine family is critical for constitutive endocytosis of the type II TGF- $\beta$ receptor. $J$. Cell. Sci. 114: 1777-1786.

Entchev, E.V., Schwabedissen, A., and Gonzalez-Gaitan, M. 2000. Gradient formation of the TGF- $\beta$ homolog Dpp. Cell 103: 981-991.

Fehon, R.G., Kooh, P.J., Rebay, I., Regan, C.L., Xu, T., Muskavitch, M.A., and Artavanis-Tsakonas, S. 1990. Molecular interactions between the protein products of the neurogenic loci Notch and Delta, two EGF-homologous genes in Drosophila. Cell 61: 523-534.

Felder, S., Miller, K., Moehren, G., Ullrich, A., Schlessinger, J., and Hopkins, C.R. 1990. Kinase activity controls the sorting of the epidermal growth factor receptor within the multivesicular body. Cell 61: 623-634.

Ferguson, E.L. and Anderson, K.V. 1992. Localized enhancement and repression of the activity of the TGF- $\beta$ family member, Decapentaplegic, is necessary for dorsal-ventral pattern formation in the Drosophila embryo. Development 114: $583-597$.

Fostier, M., Evans, D.A., Artavanis-Tsakonas, S., and Baron, M. 1998. Genetic characterization of the Drosophila melanogaster Suppressor of deltex gene: A regulator of Notch signaling. Genetics 150: 1477-1485.

Francois, V. and Bier, E. 1995. Xenopus chordin and Drosophila short gastrulation genes encode homologous proteins functioning in dorsal-ventral axis formation. Cell 80: 19-20.

Franzen, P., Heldin, C.H., and Miyazono, K. 1995. The GS domain of the transforming growth factor- $\beta$ type I receptor is important in signal transduction. Biochem. Biophys. Res. Commun. 207: 682-689.

Frise, E., Knoblich, J.A., Younger-Shepherd, S., Jan, L.Y., and Jan, Y.N. 1996. The Drosophila Numb protein inhibits signaling of the Notch receptor during cell-cell interaction in sensory organ lineage. Proc. Natl. Acad. Sci. 93: 11925-11932.

Frolik, C.A., Wakefield, L.M., Smith, D.M., and Sporn, M.B. 1984. Characterization of a membrane receptor for transforming growth factor- $\beta$ in normal rat kidney fibroblasts. $J$. Biol. Chem. 259: 10995-11000.

Futter, C.E., Pearse, A., Hewlett, L.J., and Hopkins, C.R. 1996. Multivesicular endosomes containing internalized EGFEGF receptor complexes mature and then fuse directly with lysosomes. J. Cell Biol. 132: 1011-1023.

Galan, J.M., Moreau, V., Andre, B., Volland, C., and 
Haguenauer-Tsapis, R. 1996. Ubiquitination mediated by the Npilp/Rsp5p ubiquitin-protein ligase is required for endocytosis of the yeast uracil permease. I. Biol. Chem. 271: 10946-10952.

Gelbart, W.M. 1989. The decapentaplegic gene: A TGF- $\beta$ homologue controlling pattern formation in Drosophila. Development 107: 65-74.

Gibson, M.C. and Schubiger, G. 2000. Peripodial cells regulate proliferation and patterning of Drosophila imaginal discs. Cell 103: 343-350.

Gillooly, D.J., Morrow, I.C., Lindsay, M., Gould, R., Bryant, N.J., Gaullier, J.M., Parton, R.G., and Stenmark, H. 2000. Localization of phosphatidylinositol 3-phosphate in yeast and mammalian cells. EMBO J. 19: 4577-4588.

Glenney, Jr., J.R., Chen, W.S., Lazar, C.S., Walton, G.M., Zokas, L.M., Rosenfeld, M.G., and Gill, G.N. 1988. Ligand-induced endocytosis of the EGF receptor is blocked by mutational inactivation and by microinjection of anti-phosphotyrosine antibodies. Cell 52: 675-684.

Gonzalez, F., Swales, L., Bejsovec, A., Skaer, H., and MartinezArias, A. 1991. Secretion and movement of Wingless protein in the epidermis of the Drosophila embryo. Mech. Dev. 35: 43-54.

Gonzalez-Gaitan, M. and Jackle, H. 1999. The range of spaltactivating Dpp signalling is reduced in endocytosis-defective Drosophila wing discs. Mech. Dev. 87: 143-151.

Goode, S. 2000. Germ cell cytonemes? Trends Cell. Biol. 10: 8990.

Gorvel, J.P., Chavrier, P., Zerial, M., and Stahl, P.D. 1991. Rab5 controls early endosome fusion in vitro. Cell 64: 1133.

Gout, I., Dhand, R., Hiles, I.D., Fry, M.J., Panayotou, G., Das, P., Truong, O., Totty, N.F., Hsuan, J., and Booker, G.W. 1993. The GTPase Dynamin binds to and is activated by a subset of SH3 domains. Cell 75: 25-36.

Greco, V., Hannus, M., and Eaton, S. 2001. Argosomes: A potential vehicle for the spread of morphogens through epithelia. Cell 106: 633-645.

Griffiths, G. and Gruenberg, J. 1991. The arguments for preexisting early and late endosomes. Trends Cell Biol. 1: 5 .

Guichet, A., Wucherpfennig, T., Dudu, V., Etter, S., WilschBrauniger, M., Hellwig, A., Gonzalez-Gaitan, M., Huttner, W.B., and Schmidt, A.A. 2002. Essential role of endophilin A in synaptic vesicle budding at the Drosophila neuromuscular junction. EMBO J. 21: 1661-1672.

Guo, M., Jan, L.Y., and Jan, Y.N. 1996. Control of daughter cell fates during asymmetric division: interaction of Numb and Notch. Neuron 17: 27-41.

Gurdon, J.B. and Bourillot, P.Y. 2001. Morphogen gradient interpretation. Nature 413: 797-803.

Haigler, H.T., McKanna, J.A., and Cohen, S. 1979. Direct visualization of the binding and internalization of a ferritin conjugate of epidermal growth factor in human carcinoma cells A-431. I. Cell Biol. 81: 382-395.

Hazuka, C.D., Foletti, D.L., and Scheller, R.H. 1999. Nerve terminal membrane trafficking proteins: From discovery to function. In Neurotransmitter release (ed. H.J. Bellen), pp. 81-125. Oxford University Press, New York, NY.

Henis, Y.I., Moustakas, A., Lin, H.Y., and Lodish, H.F. 1994. The types II and III transforming growth factor- $\beta$ receptors form homo-oligomers. J. Cell Biol. 126: 139-154.

Hicke, L. 2001. A new ticket for entry into budding vesiclesubiquitin. Cell 106: 527-530.

Hofmann, K. and Falquet, L. 2001. A ubiquitin-interacting motif conserved in components of the proteasomal and lysosomal protein degradation systems. Trends Biochem. Sci. 26: 347-350.

Holley, S.A., Neul, J.L., Attisano, L., Wrana, J.L., Sasai, Y.,
O'Connor, M.B., De Robertis, E.M., and Ferguson, E.L. 1996 The Xenopus dorsalizing factor Noggin ventralizes Drosophila embryos by preventing DPP from activating its receptor. Cell 86: 607-617.

Holstein, S.E., Ungewickell, H., and Ungewickell, E. 1996 Mechanism of clathrin basket dissociation: separate functions of protein domains of the DnaJ homologue Auxilin. J. Cell Biol. 135: 925-937.

Honegger, A.M., Schmidt, A., Ullrich, A., and Schlessinger, J. 1990. Separate endocytic pathways of kinase-defective and -active EGF receptor mutants expressed in same cells. J. Cell Biol. 110: 1541-1548.

Hopkins, C.R., Gibson, A., Shipman, M., and Miller, K. 1990. Movement of internalized ligand-receptor complexes along a continuous endosomal reticulum. Nature 346: 335-339.

Horiuchi, H., Lippe, K., McBride, H.M., Rubino, M., Woodman, P., Stenmark, H., Rybin, V., Wilm, M., Ashman, K., Mann, M., et al. 1997. A novel Rab5 GDP/GTP exchange factor complexed to Rabaptin-5 links nucleotide exchange to effector recruitment and function. Cell 90: 1149-1159.

Iannolo, G., Salcini, A.E., Gaidarov, I., Goodman, Jr., O.B., Baulida, J., Carpenter, G., Pelicci, P.G., Di Fiore, P.P., and Keen, J.H. 1997. Mapping of the molecular determinants involved in the interaction between Eps15 and AP-2. Cancer Res. 57: $240-245$

Incardona, J.P., Lee, J.H, Robertson, C.P., Enga, K., Kapur, R.P., and Roelink, H. 2000. Receptor-mediated endocytosis of soluble and membrane-tethered Sonic hedgehog by Patched1. Proc. Natl. Acad. Sci. 97: 12044-12049.

Ingham, P.W. and McMahon, A.P. 2001. Hedgehog signaling in animal development: paradigms and principles. Genes \& Dev. 15: 3059-3087.

Itoh, F., Asao, H., Sugamura, K., Heldin, C.H., ten Dijke, P., and Itoh, S. 2001. Promoting bone morphogenetic protein signaling through negative regulation of inhibitory Smads. EMBO J. 20: 4132-4142.

Jehn, B.M., Dittert, I., Beyer, S., von Der Mark, K., and Bielke, W. 2002. c-Cbl binding and ubiquitin dependent lysosomal degradation of membrane associated Notch1. J. Biol. Chem. 277: 8033-8040.

Joazeiro, C.A., Wing, S.S., Huang, H., Leverson, J.D., Hunter, T., and Liu, Y.C. 1999. The tyrosine kinase negative regulator $\mathrm{c}$-Cbl is a RING-type, E2-dependent ubiquitin-protein ligase. Science 286: 309-312.

Kalderon, D. 2000. Transducing the Hedgehog signal. Cell 103: 371-374.

Karpen, H.E., Bukowski, J.T., Hughes, T., Gratton, J.P., Sessa, W.C., and Gailani, M.R. 2001. The Sonic hedgehog receptor Patched associates with Caveolin-1 in cholesterol-rich microdomains of the plasma membrane. I. Biol. Chem. 276: 19503-19511.

Katzmann, D.J., Babst, M., and Emr, S.D. 2001. Ubiquitin-dependent sorting into the multivesicular body pathway requires the function of a conserved endosomal proteins sorting complex, ESCRT-I. Cell 106: 145-155.

Kavsak, P., Rasmussen, R.K., Causing, C.G., Bonni, S., Zhu, H., Thomsen, G.H., and Wrana, J.L. 2000. Smad7 binds to Smurf2 to form an E3 ubiquitin ligase that targets the TGF $\beta$ receptor for degradation. Mol. Cell 6: 1365-1375.

Kirchhausen, T., Bonifacino, J.S., and Riezman, H. 1997. Linking cargo to vesicle formation: Receptor tail interactions with coat proteins. Curr. Opin. Cell. Biol. 9: 488-495.

Kobayashi, T., Stang, E., Fang, K.S., de Moerloose, P., Parton, R.G., and Gruenberg, J. 1998. A lipid associated with the antiphospholipid syndrome regulates endosome structure and function. Nature 392: 193-197. 
Komada, M. and Kitamura, N. 2001. Hrs and hbp: Possible regulators of endocytosis and exocytosis. Biochem. Biophys. Res. Commun. 281: 1065-1069.

Komada, M. and Soriano, P. 1999. Hrs, a FYVE finger protein localized to early endosomes, is implicated in vesicular traffic and required for ventral folding morphogenesis. Genes \& Dev. 13: 1475-1485.

Kooh, P.J., Fehon, R.G., and Muskavitch, M.A. 1993. Implications of dynamic patterns of Delta and Notch expression for cellular interactions during Drosophila development. Development 117: 493-507.

Kramer, H. 2001. Neuralized: Regulating Notch by putting away Delta. Dev. Cell 1: 725-726.

Kranenburg, O., Verlaan, I., and Moolenaar, W.H. 1999. Dynamin is required for the activation of mitogen-activated protein (MAP) kinase by MAP kinase kinase. J. Biol. Chem. 274: 35301-35304.

Kurten, R.C., Cadena, D.L., and Gill, G.N. 1996. Enhanced degradation of EGF receptors by a sorting nexin, SNX1. Science 272: 1008-1010.

Lai, E.C., Deblandre, G.A., Kintner, C., and Rubin, G.M. 2001. Drosophila Neuralized is a ubiquitin ligase that promotes the internalization and degradation of Delta. Dev. Cell 1: 783-794.

Lai, W.H., Cameron, P.H., Doherty II, J.J., Posner, B.I., and Bergeron, J.J. 1989. Ligand-mediated autophosphorylation activity of the epidermal growth factor receptor during internalization. I. Cell Biol. 109: 2751-2760.

Lamaze, C. and Schmid, S.L. 1995. Recruitment of epidermal growth factor receptors into coated pits requires their activated tyrosine kinase. J. Cell Biol. 129: 47-54.

Langdon, W.Y., Hartley, J.W., Klinken, S.P., Ruscetti, S.K., and Morse III, H.C. 1989. v-Cbl, an oncogene from a dual-recombinant murine retrovirus that induces early B-lineage lymphomas. Proc. Natl. Acad. Sci. 86: 1168-1172.

Lecuit, T. and Cohen, S.M. 1998. Dpp receptor levels contribute to shaping the Dpp morphogen gradient in the Drosophila wing imaginal disc. Development 125: 4901-4907.

Lee, J.J., von Kessler, D.P., Parks, S., and Beachy, P.A. 1992. Secretion and localized transcription suggest a role in positional signaling for products of the segmentation gene hedgehog. Cell 71: 33-50.

Lenferink, A.E., Pinkas-Kramarski, R., van de Poll, M.L., van Vugt, M.J., Klapper, L.N., Tzahar, E., Waterman, H., Sela, M., van Zoelen, E.J., and Yarden, Y. 1998. Differential endocytic routing of homo- and hetero-dimeric ErbB tyrosine kinases confers signaling superiority to receptor heterodimers. EMBO I. 17: 3385-3397.

Leof, E.B. 2000. Growth factor receptor signalling: Location, location, location. Trends Cell Biol. 10: 343-348.

Levkowitz, G., Waterman, H., Zamir, E., Kam, Z., Oved, S., Langdon, W.Y., Beguinot, L., Geiger, B., and Yarden, Y. 1998. c-Cbl/Sli-1 regulates endocytic sorting and ubiquitination of the epidermal growth factor receptor. Genes \& Dev. 12 3663-3674.

Levkowitz, G., Waterman, H., Ettenberg, S.A., Katz, M., Tsygankov, A.Y., Alroy, I., Lavi, S., Iwai, K., Reiss, Y., Ciechanover, A., et al. 1999. Ubiquitin ligase activity and tyrosine phosphorylation underlie suppression of growth factor signaling by c-Cbl/Sli-1. Mol. Cell 4: 1029-1040.

Lewis, P.M., Dunn, M.P., McMahon, J.A., Logan, M., Martin, J.F., St-Jacques, B., and McMahon, A.P. 2001. Cholesterol modification of Sonic hedgehog is required for long-range signaling activity and effective modulation of signaling by Ptc1. Cell 105: 599-612.

Li, G., D'Souza-Schorey, C., Barbieri, M.A., Roberts, R.L., Klip- pel, A., Williams, L.T., and Stahl, P.D. 1995. Evidence for phosphatidylinositol 3-kinase as a regulator of endocytosis via activation of Rab5. Proc. Natl. Acad. Sci. 92: 10207-10211.

Li, L., Liao, J., Ruland, J., Mak, T.W., and Cohen, S.N. 2001. A TSG101/MDM2 regulatory loop modulates MDM2 degradation and MDM2/p53 feedback control. Proc. Natl. Acad. Sci. 98: 1619-1624.

Lieber, T., Kidd, S., and Young, M.W. 2002. Kuzbanian-mediated cleavage of Drosophila Notch. Genes \& Dev. 16: 209-221.

Lill, N.L., Douillard, P., Awwad, R.A., Ota, S., Lupher, M.L.J., Miyake, S., Meissner-Lula, N., Hsu, V.W., and Band, H. 2000 The evolutionarily conserved $\mathrm{N}$-terminal region of $\mathrm{Cbl}$ is sufficient to enhance down-regulation of the epidermal growth factor receptor. J. Biol. Chem. 275: 367-377.

Lin, S.Y., Makino, K., Xia, W., Martin, A., Wen, Y., Kwong, K.Y., Bourguignon, L., and Hung, M.C. 2001. Nuclear localization of EGF receptor and its potential new role as a transcription factor. Nat. Cell Biol. 3: 802-808.

Lin, X., Liang, M., and Feng, X.H. 2000. Smurf2 is a ubiquitin E3 ligase mediating proteasome-dependent degradation of Smad2 in transforming growth factor- $\beta$ signaling. J. Biol. Chem. 275: 36818-36822.

Liscum, L. and Faust, J.R. 1987. Low-density lipoprotein (LDL)mediated suppression of cholesterol synthesis and LDL uptake is defective in Niemann-Pick type C fibroblasts. J. Biol. Chem. 262: 17002-17008.

Lloyd, T., Atkinson, R., Wu, M.N., Pennetta, G., and Bellen, H.J. 2002. HRS is required for endosome to lysosome trafficking and tyrosine kinase signaling. Cell 108: 261-269.

Lloyd, V., Ramaswami, M., and Kramer, H. 1998. Not just pretty eyes: Drosophila eye-colour mutations and lysosomal delivery. Trends Cell Biol. 8: 257-259.

Lohi, O. and Lehto, V.P. 1998. VHS domain marks a group of proteins involved in endocytosis and vesicular trafficking. FEBS Lett. 440: 255-257.

Lohi, O., Poussu, A., Merilainen, J., Kellokumpu, S., Wasenius, V.M., and Lehto, V.P. 1998. EAST, an epidermal growth factor receptor- and Eps15-associated protein with Src homology 3 and tyrosine-based activation motif domains. J. Biol. Chem. 273: 21408-21415.

Marigo, V., Scott, M.P., Johnson, R.L., Goodrich, L.V., and Tabin, C.J. 1996. Conservation in Hedgehog signaling: Induction of a chicken Patched homolog by Sonic hedgehog in the developing limb. Development 122: 1225-1233.

Marks, B., Stowell, M.H., Vallis, Y., Mills, I.G., Gibson, A., Hopkins, C.R., and McMahon, H.T. 2001. GTPase activity of Dynamin and resulting conformation change are essential for endocytosis. Nature 410: 231-235

Marques, G., Musacchio, M., Shimell, M.J., WunnenbergStapleton, K., Cho, K.W., and O'Connor, M.B. 1997. Production of a DPP activity gradient in the early Drosophila embryo through the opposing actions of the SOG and TLD proteins. Cell 91: 417-426.

Martin, V., Carrillo, G., Torroja, C., and Guerrero, I. 2001. The sterol-sensing domain of Patched protein seems to control Smoothened activity through Patched vesicular trafficking. Curr. Biol. 11: 601-607.

Massague, J. 1998. TGF- $\beta$ signal transduction. Annu. Rev. Biochem. 67: 753-791.

- 2000. How cells read TGF- $\beta$ signals. Nat. Rev. Mol. Cell. Biol. 1: 169-178.

Massague, J. and Kelly, B. 1986. Internalization of transforming growth factor- $\beta$ and its receptor in BALB/c 3T3 fibroblasts. $J$. Cell. Physiol. 128: 216-222.

Mastronardi, F.G., Dimitroulakos, J., Kamel-Reid, S., and Manoukian, A.S. 2000. Colocalization of Patched and acti- 
vated Sonic hedgehog to lysosomes in neurons. Neuroreport 11: $581-585$.

McBride, H.M., Rybin, V., Murphy, C., Giner, A., Teasdale, R., and Zerial, M. 1999. Oligomeric complexes link Rab5 effectors with NSF and drive membrane fusion via interactions between EEA1 and Syntaxin 13. Cell 98: 377-386.

McLauchlan, H., Newell, J., Morrice, N., Osborne, A., West, M., and Smythe, E. 1998. A novel role for Rab5-GDI in ligand sequestration into clathrin-coated pits. Curr. Biol. 8: 34-45.

McNiven, M.A. 1998. Dynamin: A molecular motor with pinchase action. Cell 94: 151-154.

Meisner, H., Daga, A., Buxton, J., Fernandez, B., Chawla, A., Banerjee, U., and Czech, M.P. 1997. Interactions of Drosophila $\mathrm{Cbl}$ with epidermal growth factor receptors and role of $\mathrm{Cbl}$ in R7 photoreceptor cell development. Mol. Cell. Biol. 17: 2217-2225.

Miura, S., Takeshita, T., Asao, H., Kimura, Y., Murata, K., Sasaki, Y., Hanai, J.I., Beppu, H., Tsukazaki, T., Wrana, J.L., et al. 2000. Hgs (Hrs), a FYVE domain protein, is involved in Smad signaling through cooperation with SARA. Mol. Cell. Biol. 20: 9346-9355.

Moline, M.M., Southern, C., and Bejsovec, A. 1999. Directionality of Wingless protein transport influences epidermal patterning in the Drosophila embryo. Development 126: 4375-4384.

Morisato, D. and Anderson, K.V. 1995. Signaling pathways that establish the dorsal-ventral pattern of the Drosophila embryo. Annu. Rev. Genet. 29: 371-399.

Mullock, B.M., Smith, C.W., Ihrke, G., Bright, N.A., Lindsay, M., Parkinson, E.J., Brooks, D.A., Parton, R.G., James, D.E., Luzio, J.P., et al. 2000. Syntaxin 7 is localized to late endosome compartments, associates with Vamp 8, and is required for late endosome-lysosome fusion. Mol. Biol. Cell 11: 3137-3153.

Muramatsu, M., Yan, J., Eto, K., Tomoda, T., Yamada, R., and Arai, K. 1997. A chimeric serine/threonine kinase receptor system reveals the potential of multiple type II receptors to cooperate with transforming growth factor- $\beta$ type I receptor. Mol. Biol. Cell 8: 469-480.

Murone, M., Rosenthal, A., and de Sauvage, F.J. 1999. Sonic hedgehog signaling by the Patched-Smoothened receptor complex. Curr. Biol. 9: 76-84.

Murphy, R.F. 1991. Maturation models for endosome and lysosome biogenesis. Trends Cell Biol. 1: 77-82.

Nakano, Y., Guerrero, I., Hidalgo, A., Taylor, A., Whittle, J.R., and Ingham, P.W. 1989. A protein with several possible membrane-spanning domains encoded by the Drosophila segment polarity gene patched. Nature 341: 508-513.

Nellen, D., Burke, R., Struhl, G., and Basler, K. 1996. Direct and long-range action of a DPP morphogen gradient. Cell 85: 357-368.

Nesterov, A., Lysan, S., Vdovina, I., Nikolsky, N., and Fujita, D.J. 1994. Phosphorylation of the epidermal growth factor receptor during internalization in A-431 cells. Arch. Biochem. Biophys. 313: 351-359.

Newmyer, S.L. and Schmid, S.L. 2001. Dominant-interfering Hsc70 mutants disrupt multiple stages of the clathrin-coated vesicle cycle in vivo. J. Cell Biol. 152: 607-620.

Nielsen, E., Severin, F., Backer, J.M., Hyman, A.A., and Zerial, M. 1999. Rab5 regulates motility of early endosomes on microtubules. Nat. Cell Biol. 1: 376-382.

Nohturfft, A., DeBose-Boyd, R.A., Scheek, S., Goldstein, J.L., and Brown, M.S. 1999. Sterols regulate cycling of SREBP cleavage-activating protein (SCAP) between endoplasmic reticulum and Golgi. Proc. Natl. Acad. Sci. 96: 11235-11240.

Odorizzi, G., Babst, M., and Emr, S.D. 1998a. Fablp PtdIns(3)P 5 -kinase function essential for protein sorting in the multi- vesicular body. Cell 95: 847-858.

Odorizzi, G., Cowles, C.R., and Emr, S.D. 1998b. The AP-3 complex: A coat of many colours. Trends Cell Biol. 8: 282-288.

Opresko, L.K., Chang, C.P., Will, B.H., Burke, P.M., Gill, G.N., and Wiley, H.S. 1995. Endocytosis and lysosomal targeting of epidermal growth factor receptors are mediated by distinct sequences independent of the tyrosine kinase domain. $I$. Biol. Chem. 270: 4325-4333.

Oskvold, M.P., Skarpen, E., Lindeman, B., Roos, N., and Huitfeldt, H.S. 2000. Immunocytochemical localization of Shc and activated EGF receptor in early endosomes after EGF stimulation of HeLa cells. J. Histochem. Cytochem. 48: 21-33.

Pai, L.M., Barcelo, G., and Schupbach, T. 2000. D-cbl, a negative regulator of the EGFR pathway, is required for dorsoventral patterning in Drosophila oogenesis. Cell 103: 51-61.

Pan, D. and Rubin, G.M. 1997. Kuzbanian controls proteolytic processing of Notch and mediates lateral inhibition during Drosophila and vertebrate neurogenesis. Cell 90: 271-280.

Panin, V.M. and Irvine, K.D. 1998. Modulators of Notch signaling. Semin. Cell. Dev. Biol. 9: 609-617.

Parks, A.L., Turner, F.R., and Muskavitch, M.A. 1995. Relationships between complex Delta expression and the specification of retinal cell fates during Drosophila eye development. Mech. Dev. 50: 201-216.

Parks, A.L., Klueg, K.M., Stout, J.R., and Muskavitch, M.A 2000. Ligand endocytosis drives receptor dissociation and activation in the Notch pathway. Development 127: 1373-1385

Pavlopoulos, E., Pitsouli, C., Klueg, K.M., Muskavitch, M.A., Moschonas, N.K., and Delidakis, C. 2001. Neuralized encodes a peripheral membrane protein involved in Delta sig naling and endocytosis. Dev. Cell 1: 807-816.

Pentchev, P.G., Comly, M.E., Kruth, H.S., Vanier, M.T., Wenger, D.A., Patel, S., and Brady, R.O. 1985. A defect in cholesterol esterification in Niemann-Pick disease (type C) patients. Proc. Natl. Acad. Sci. 82: 8247-8251.

Peters, P.J., Gao, M., Gaschet, J., Ambach, A., van Donselaar, E., Traverse, J.F., Bos, E., Wolffe, E.J., and Hsu, V.W. 2001. Characterization of coated vesicles that participate in endocytic recycling. Traffic 2: 885-895.

Petrelli, A., Gilestro, G.F., Lanzardo, S., Comoglio, P.M., Migone, N., and Giordano, S. 2002. The endophilin-CIN85-Cbl complex mediates ligand-dependent downregulation of c-Met. Nature 416: 187-190.

Piper, R.C. and Luzio, J.P. 2001. Late endosomes: Sorting and partitioning in multivesicular bodies. Traffic 2: 612-621.

Piper, R.C., Cooper, A.A., Yang, H., and Stevens, T.H. 1995 VPS27 controls vacuolar and endocytic traffic through a prevacuolar compartment in Saccharomyces cerevisiae. J. Cell Biol. 131: 603-617.

Pitcher, C., Honing, S., Fingerhut, A., Bowers, K., and Marsh, M. 1999. Cluster of differentiation antigen 4 (CD4) endocytosis and adaptor complex binding require activation of the CD4 endocytosis signal by serine phosphorylation. Mol. Biol. Cell 10: 677-691.

Podos, S.D., Hanson, K.K., Wang, Y.C., and Ferguson, E.L. 2001. The DSmurf ubiquitin-protein ligase restricts BMP signaling spatially and temporally during Drosophila embryogenesis. Dev. Cell 1: 567-578.

Polakis, P. 2000. Wnt signaling and cancer. Genes \& Dev. 14: $1837-1851$.

Polo, S., Sigismund, S., Faretta, M., Guidi, M., Capua, M.R., Bossi, G., Chen, H., De Camilli, P., and Di Fiore, P.P. 2002. A single motif responsible for ubiquitin recognition and monoubiquitination in endocytic proteins. Nature 416: 451-455.

Porter, J.A., von Kessler, D.P., Ekker, S.C., Young, K.E., Lee, J.J., Moses, K., and Beachy, P.A. 1995. The product of Hedgehog 
autoproteolytic cleavage active in local and long-range signaling. Nature 374: 363-366.

Porter, J.A., Young, K.E., and Beachy, P.A. 1996. Cholesterol modification of Hedgehog signaling proteins in animal development. Science 274: 255-259.

Poodry, C.A. 1990. shibire, a neurogenic mutant of Drosophila. Dev. Biol. 138: 464-472.

Qiu, L., Joazeiro, C., Fang, N., Wang, H.Y., Elly, C., Altman, Y., Fang, D., Hunter, T., and Liu, Y.C. 2000. Recognition and ubiquitination of Notch by Itch, a hect-type E3 ubiquitin ligase. J. Biol. Chem. 275: 35734-35737.

Ramirez-Weber, F.A. and Kornberg, T.B. 1999. Cytonemes: Cellular processes that project to the principal signaling center in Drosophila imaginal discs. Cell 97: 599-607.

Raths, S., Rohrer, J., Crausaz, F., and Riezman, H. 1993. end3 and end4: Two mutants defective in receptor-mediated and fluid-phase endocytosis in Saccharomyces cerevisiae. J. Cell Biol. 120: 55-65.

Raymond, C.K., Howald-Stevenson, I., Vater, C.A., and Stevens, T.H. 1992. Morphological classification of the yeast vacuolar protein-sorting mutants: Evidence for a prevacuolar compart ment in class E vps mutants. Mol. Biol. Cell 3: 1389-1402.

Reichsman, F., Smith, L., and Cumberledge, S. 1996. Glycosaminoglycans can modulate extracellular localization of the Wingless protein and promote signal transduction. J. Cell Biol. 135: 819-827.

Rietveld, A., Neutz, S., Simons, K., and Eaton, S. 1999. Association of sterol- and glycosylphosphatidylinositol-linked proteins with Drosophila raft lipid microdomains. J. Biol. Chem. 274: 12049-12054.

Ringstad, N., Nemoto, Y., and De Camilli, P. 1997. The SH3p4/ Sh3p8/SH3p13 protein family: Binding partners for Synaptojanin and Dynamin via a Grb2-like Src homology 3 domain. Proc. Natl. Acad. Sci. 94: 8569-8574.

Robinson, J.S., Klionsky, D.J., Banta, L.M., and Emr, S.D. 1988. Protein sorting in Saccharomyces cerevisiae: Isolation of mutants defective in the delivery and processing of multiple vacuolar hydrolases. Mol. Cell. Biol. 8: 4936-4948.

Rothman, J.H. and Stevens, T.H. 1986. Protein sorting in yeast: Mutants defective in vacuole biogenesis mislocalize vacuolar proteins into the late secretory pathway. Cell 47: 1041-1051.

Rotin, D., Staub, O., and Haguenauer-Tsapis, R. 2000. Ubiquitination and endocytosis of plasma membrane proteins: role of Nedd4/Rsp5p family of ubiquitin-protein ligases. J. Membr. Biol. 176: 1-17.

Sakamoto, K., Ohara, O., Takagi, M., Takeda, S., and Katsube, K. 2002. Intracellular cell-autonomous association of Notch and its ligands: A novel mechanism of Notch signal modification. Dev. Biol. 241: 313-326.

Sanson, B., Alexandre, C., Fascetti, N., and Vincent, J.P. 1999. Engrailed and Hedgehog make the range of Wingless asymmetric in Drosophila embryos. Cell 98: 207-216.

Santolini, E., Puri, C., Salcini, A.E., Gagliani, M.C., Pelicci, P.G., Tacchetti, C., and Di Fiore, P.P. 2000. Numb is an endocytic protein. J. Cell Biol. 151: 1345-1352.

Sathre, K.A., Tsang, M.L., Weatherbee, J.A., and Steer, C.J. 1991. Binding and internalization of transforming growth factor- $\beta$ 1 by human hepatoma cells: evidence for receptor recycling. Hepatology 14: 287-295.

Schmidt, A., Wolde, M., Thiele, C., Fest, W., Kratzin, H., Podtelejnikov, A.V., Witke, W., Huttner, W.B., and Soling, H.D. 1999. Endophilin I mediates synaptic vesicle formation by transfer of arachidonate to lysophosphatidic acid. Nature 401: 133-141.

Schweitzer, R., Shaharabany, M., Seger, R., and Shilo, B.Z. 1995. Secreted Spitz triggers the DER signaling pathway and is a limiting component in embryonic ventral ectoderm determination. Genes \& Dev. 9: 1518-1529.

Seaman, M.N.J. and Luzio, J.P. 2001. Lysosomes and other late compartments of the endocytic pathway. Oxford University Press, New York, NY.

Seugnet, L., Simpson, P., and Haenlin, M. 1997. Requirement for Dynamin during Notch signaling in Drosophila neurogenesis. Dev. Biol. 192: 585-598.

Sever, S., Muhlberg, A.B., and Schmid, S.L. 1999. Impairment of dynamin's GAP domain stimulates receptor-mediated endocytosis. Nature 398: 481-486.

Simonsen, A., Lippe, R., Christoforidis, S., Gaullier, J.M., Brech, A., Callaghan, J., Toh, B.H., Murphy, C., Zerial, M., and Stenmark, H. 1998. EEA1 links PI(3)K function to Rab5 regulation of endosome fusion. Nature 394: 494-498.

Soubeyran, P., Kowanetz, K., Szymkiewicz, I., Langdon, W.Y., and Dickic, I. 2002. Cbl-CIN85-endophilin complex mediates ligand-induced downregulation of EGF receptors. $\mathrm{Na}$ ture 416: 183-187.

Spormann, D.O., Heim, J., and Wolf, D.H. 1992. Biogenesis of the yeast vacuole (lysosome). The precursor forms of the soluble hydrolase carboxypeptidase yscS are associated with the vacuolar membrane. J. Biol. Chem. 267: 8021-8029.

Srinivasan, S., Rashka, K.E., and Bier, E. 2002. Creation of a SOG morphogen gradient in the Drosophila embryo. Dev. Cell 2: 91-101.

Stang, E., Johannessen, L.E., Knardal, S.L., and Madshus, I.H. 2000. Polyubiquitination of the epidermal growth factor receptor occurs at the plasma membrane upon ligand-induced activation. J. Biol. Chem. 275: 13940-13947.

Stenmark, H. and Zerial, M. 2001. Molecular mechanisms of membrane fusion in the endocytic pathway. In Frontiers in molecular biology (ed. M. Marsh), pp. 94-110. Oxford University Press, New York, NY.

Stenmark, H., Parton, R.G., Steele-Mortimer, O., Lutcke, A., Gruenberg, J., and Zerial, M. 1994. Inhibition of Rab5 GTPase activity stimulates membrane fusion in endocytosis. EMBO J. 13: 1287-1296.

Stenmark, H., Aasland, R., Toh, B.-H. and D'Arrigo, A. 1996. Endosomal localization of the autoantigen EEA1 is mediated by a zinc-binding FYVE finger. J. Biol. Chem. 271: 2404824054.

Stevens, T.H., Rothman, J.H., Payne, G.S., and Schekman, R. 1986. Gene dosage-dependent secretion of yeast vacuolar carboxypeptidase Y. J. Cell Biol. 102: 1551-1557.

Stone, D.M., Hynes, M., Armanini, M., Swanson, T.A., Gu, Q., Johnson, R.L., Scott, M.P., Pennica, D., Goddard, A., Phillips, H., et al. 1996. The tumour-suppressor gene patched encodes a candidate receptor for Sonic hedgehog. Nature 384: 129-134.

Strigini, M. and Cohen, S.M. 1999. Formation of morphogen gradients in the Drosophila wing. Semin. Cell. Dev. Biol. 10: $335-344$.

2000. Wingless gradient formation in the Drosophila wing. Curr. Biol. 10: 293-300.

Struhl, G. and Adachi, A. 1998. Nuclear access and action of Notch in vivo. Cell 93: 649-660.

Struhl, G. and Greenwald, I. 1999. Presenilin is required for activity and nuclear access of Notch in Drosophila. Nature 398: 522-525.

Strutt, H., Thomas, C., Nakano, Y., Stark, D., Neave, B., Taylor, A.M., and Ingham, P.W. 2001. Mutations in the sterol-sensing domain of Patched suggest a role for vesicular trafficking in Smoothened regulation. Curr. Biol. 11: 608-613.

Takata, H., Kato, M., Denda, K., and Kitamura, N. 2000. An Hrs binding protein having a Src homology 3 domain is involved 
in intracellular degradation of growth factors and their receptors. Genes Cells 5: 57-69.

Takeshita, T., Arita, T., Higuchi, M., Asao, H., Endo, K., Kuroda, H., Tanaka, N., Murata, K., Ishii, N., and Sugamura, K. 1997. STAM, signal transducing adaptor molecule, is associated with Janus kinases and involved in signaling for cell growth and c-myc induction. Immunity 6: 449-457.

Tanaka, N., Kaneko, K., Asao, H., Kasai, H., Endo, Y., Fujita, T., Takeshita, T., and Sugamura, K. 1999. Possible involvement of a novel STAM-associated molecule 'AMSH' in intracellular signal transduction mediated by cytokines. J. Biol. Chem. 274: 19129-19135.

Taylor, A.M., Nakano, Y., Mohler, J., and Ingham, P.W. 1993. Contrasting distributions of Patched and Hedgehog proteins in the Drosophila embryo. Mech. Dev. 42: 89-96.

Teleman, A.A. and Cohen, S.M. 2000. Dpp gradient formation in the Drosophila wing imaginal disc. Cell 103: 971-980.

Teleman, A.A., Strigini, M., and Cohen, S.M. 2001. Shaping morphogen gradients. Cell 105: 559-562.

Tooze, S.A. 2001. Cell biology. GGAs tie up the loose ends Science 292: 1663-1665.

Tsruya, R., Schlesinger, A., Reich, A., Gabay, L., Sapir, A., and Shilo, B.Z. 2002. Intracellular trafficking by Star regulates cleavage of the Drosophila EFG receptor ligand Spitz. Genes \& Dev. 16: 222-234.

Tsukazaki, T., Chiang, T.A., Davison, A.F., Attisano, L., and Wrana, J.L. 1998. SARA, a FYVE domain protein that recruits Smad2 to the TGF $\beta$ receptor. Cell 95: 779-791.

Urban, S., Lee, J.R., and Freeman, M. 2001. Drosophila rhomboid-1 defines a family of putative intramembrane serine proteases. Cell 107: 173-182.

van den Heuvel, M., Nusse, R., Johnston, P., and Lawrence, P.A. 1989. Distribution of the wingless gene product in Drosophila embryos: A protein involved in cell-cell communication. Cell 59: 739-749.

van der Bliek, A.M. 1999. Is Dynamin a regular motor or a master regulator? Trends Cell Biol. 9: 253-254.

Verstreken, P., Kjærulff, O., Lloyd, T., Atkinson, R., and Bellen, H.J. 2002. Drosophila Endophilin mutations block clathrinmediated endocytosis but not neurotransmitter release. Cell 109: $101-112$

Vieira, A.V., Lamaze, C., and Schmid, S.L. 1996. Control of EGF receptor signaling by clathrin-mediated endocytosis. Science 274: 2086-2089.

Wakefield, L.M., Smith, D.M., Masui, T., Harris, C.C., and Sporn, M.B. 1987. Distribution and modulation of the cellular receptor for transforming growth factor- $\beta$. J. Cell Biol. 105: 965-975.

Wang, L.H., Sudhof, T.C., and Anderson, R.G. 1995. The appendage domain of alpha-adaptin is a high affinity binding site for Dynamin. J. Biol. Chem. 270: 10079-10083.

Ware, M.F., Tice, D.A., Parsons, S.J., and Lauffenburger, D.A 1997. Overexpression of cellular Src in fibroblasts enhances endocytic internalization of epidermal growth factor receptor. J. Biol. Chem. 272: 30185-30190.

Waterman, H. and Yarden, Y. 2001. Molecular mechanisms underlying endocytosis and sorting of ErbB receptor tyrosine kinases. FEBS Lett. 490: 142-152.

Waterman, H., Levkowitz, G., Alroy, I., and Yarden, Y. 1999. The RING finger of c-Cbl mediates the desensitization of the epidermal growth factor receptor. J. Biol. Chem. 274: 2215122154.

Wells, A., Welsh, J.B., Lazar, C.S., Wiley, H.S., Gill, G.N., and Rosenfeld, M.G. 1990. Ligand-induced transformation by a noninternalizing epidermal growth factor receptor. Science 247: 962-964.
Wendland, B. and Emr, S.D. 1998. Pan1p, yeast Eps15, functions as a multivalent adaptor that coordinates protein-protein interactions essential for endocytosis. J. Cell Biol. 141: 71-84.

Wieser, R., Wrana, J.L., and Massague, J. 1995. GS domain mutations that constitutively activate TGF- $\beta$ R-I, the downstream signaling component in the TGF- $\beta$ receptor complex. EMBO J. 14: 2199-2208.

Wilde, A., Beattie, E.C., Lem, L., Riethof, D.A., Liu, S.H., Mobley, W.C., Soriano, P., and Brodsky, F.M. 1999. EGF receptor signaling stimulates SRC kinase phosphorylation of clathrin, influencing clathrin redistribution and EGF uptake. Cell 96: 677-687.

Wodarz, A. and Nusse, R. 1998. Mechanisms of Wnt signaling in development. Annu. Rev. Cell. Dev. Biol 14: 59-88.

Wong, W.T., Schumacher, C., Salcini, A.E., Romano, A., Castagnino, P., Pelicci, P.G., and Di Fiore, P. 1995. A proteinbinding domain, $\mathrm{EH}$, identified in the receptor tyrosine kinase substrate Eps15 and conserved in evolution. Proc. Natl. Acad. Sci. 92: 9530.

Wrana, J.L., Attisano, L., Carcamo, J., Zentella, A., Doody, J., Laiho, M., Wang, X.F., and Massague, J. 1992. TGFß signals through a heteromeric protein kinase receptor complex. Cell 71: 1003-1014.

Wrana, J.L., Attisano, L., Wieser, R., Ventura, F., and Massague, J. 1994. Mechanism of activation of the TGF- $\beta$ receptor. $\mathrm{Na}$ ture 370: 341-347.

$\mathrm{Xu}, \mathrm{T}$. and Artavanis-Tsakonas, S. 1990. deltex, a locus interacting with the neurogenic genes, Notch, Delta, and Mastermind in Drosophila melanogaster. Genetics 126: 665-677.

Ye, Y., Lukinova, N., and Fortini, M.E. 1999. Neurogenic phenotypes and altered Notch processing in Drosophila Presenilin mutants. Nature 398: 525-529.

Yeh, E., Zhou, L., Rudzik, N., and Boulianne, G.L. 2000. Neuralized functions cell autonomously to regulate Drosophila sense organ development. EMBO J. 19: 4827-4837.

Yoon, C.H., Lee, J., Jongeward, G.D., and Sternberg, P.W. 1995. Similarity of sli-1, a regulator of vulval development in $C$. elegans, to the mammalian proto-oncogene c-cbl. Science 269: 1102-1105

Zeng, X., Goetz, J.A., Suber, L.M., Scott, Jr., W.J., Schreiner, C.M., and Robbins, D.J. 2001. A freely diffusible form of Sonic hedgehog mediates long-range signalling. Nature 411: 716-720.

Zhong, W., Feder, J.N., Jiang, M.M., Jan, L.Y., and Jan, Y.N. 1996. Asymmetric localization of a mammalian Numb homolog during mouse cortical neurogenesis. Neuron 17: 4353.

Zhu, H., Kavsak, P., Abdollah, S., Wrana, J.L., and Thomsen, G.H. 1999. A SMAD ubiquitin ligase targets the BMP pathway and affects embryonic pattern formation. Nature 400: $687-693$

Zoladek, T., Tobiasz, A., Vaduva, G., Boguta, M., Martin, N.C., and Hopper, A.K. 1997. MDP1, a Saccharomyces cerevisiae gene involved in mitochondrial/cytoplasmic protein distribution, is identical to the ubiquitin-protein ligase gene RSP5. Genetics 145: 595-603.

Zwaagstra, J.C., Kassam, Z., and O'Connor-Mccourt, M.D. 1999. Down-regulation of transforming growth factor- $\beta$ receptors: Cooperativity between the types I, II, and III receptors and modulation at the cell surface. Exp. Cell. Res. 252: $352-362$

Zwaagstra, J.C., El-Alfy, M., and O'Connor-McCourt, M.D. 2001. transforming growth factor (TGF)- $\beta 1$ internalization Modulation by ligand interaction with TGF- $\beta$ receptors types I and II and a mechanism that is distinct from clathrinmediated endocytosis. J. Biol. Chem. 276: 27237-27245. 


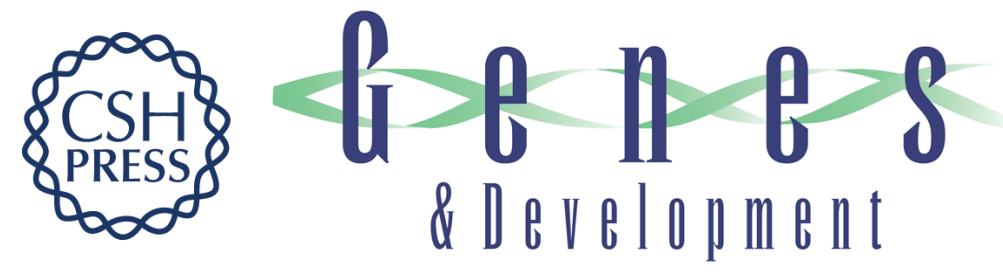

\section{When cell biology meets development: endocytic regulation of signaling pathways}

Elaine S. Seto, Hugo J. Bellen and Thomas E. Lloyd

Genes Dev. 2002, 16:

Access the most recent version at doi:10.1101/gad.989602

$\begin{array}{ll}\text { References } & \begin{array}{l}\text { This article cites } 241 \text { articles, } 106 \text { of which can be accessed free at: } \\ \text { http://genesdev.cshlp.org/content/16/11/1314.full.html\#ref-list-1 }\end{array}\end{array}$

License

Email Alerting Receive free email alerts when new articles cite this article - sign up in the box at the top Service right corner of the article or click here.

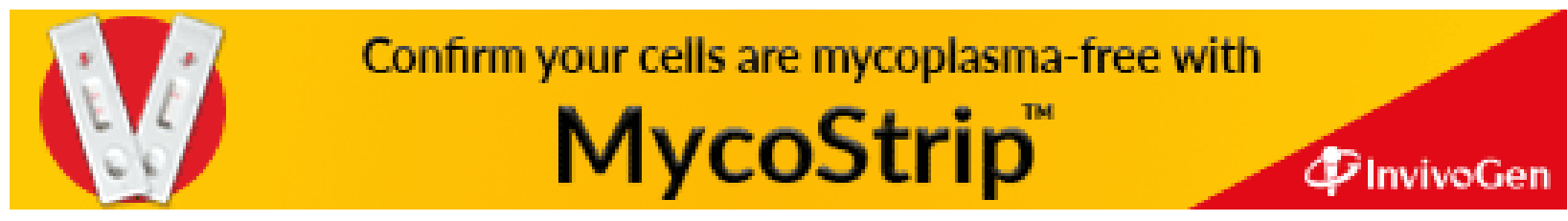

